\title{
Molecular insight on the non-covalent interactions between carbapenems and L, D-Transpeptidase 2 from Mycobacterium tuberculosis: ONIOM study
}

\author{
Thandokuhle Ntombela, ${ }^{a}$ Zeynab Fakhar, ${ }^{b}$ Collins U. Ibeji, a Thavendran Govender, ${ }^{a}$

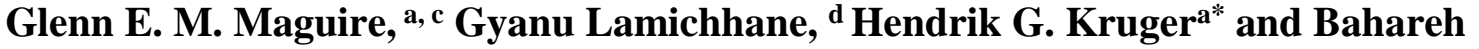 \\ Honarparvar ${ }^{a *}$
}
${ }^{a}$ Catalysis and Peptide Research Unit, School of Health Sciences, University of KwaZulu-Natal, Durban 4001, South Africa.
bepartment of Chemistry, Faculty of Natural and Agricultural Sciences, University of Pretoria, Lynnwood Road, Hatfield 0002, Pretoria, South Africa.

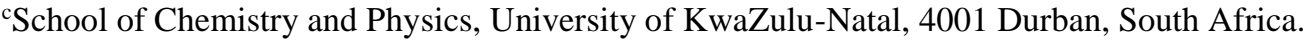
${ }^{\mathrm{d}}$ Center for Tuberculosis Research, Division of Infectious Diseases, School of Medicine, Johns Hopkins University, Baltimore, MD 21205, USA.

\begin{abstract}
*Corresponding authors: baha.honarparvar@gmail.com (Dr Bahareh Honarparvar), (Prof. Hendrik G. Kruger) kruger@ukzn.ac.za, Telephone: + 2731 2601845, Fax: +27 31 2603091, Catalysis and Peptide Research Unit, School of Health Sciences, University of KwaZulu-Natal, Durban 4041, South Africa.
\end{abstract}

\begin{abstract}
Tuberculosis remains a dreadful disease that has claimed many human lives worldwide. Elimination of the causative agent Mycobacterium tuberculosis remains elusive. Multidrugresistant TB is rapidly increasing worldwide; therefore, there is an urgent need for improving the current antibiotics and novel drug targets to successfully curb the TB burden. L, Dtranspeptidase 2 is an essential protein in $M t b$ that is responsible for virulence and growth during the chronic stage of the disease. Both D, D- and L, D-transpeptidases need to be inhibited concurrently to eradicate the bacterium. It was recently discovered that classic penicillins only inhibit D, D-transpeptidases, while L, D transpeptidases are blocked by carbapenems. This has contributed to drug resistance and persistence of tuberculosis. Herein, a hybrid two-layered ONIOM (B3LYP/6-31G+(d):AMBER) model was used to extensively investigate the binding interactions of $\mathrm{Ldt}_{\mathrm{Mt} 2}$ complexed with four carbapenems (biapenem, imipenem, meropenem, and tebipenem) to ascertain molecular insight of the drug-enzyme complexation event. In the studied complexes, the carbapenems together with catalytic triad active site residues of $\mathrm{Ldt}_{\mathrm{Mt} 2}$ (His 187, Ser188 and Cys205) were treated at with QM [B3LYP/6$31+\mathrm{G}(\mathrm{d})$ ], while the remaining part of the complexes were treated at MM level (AMBER force field). The resulting Gibbs free energy $(\Delta \mathrm{G})$, enthalpy $(\Delta \mathrm{H})$ and entropy $(\Delta \mathrm{S})$ for all complexes showed that the carbapenems exhibit reasonable binding interactions towards Ldt $_{\mathrm{Mt} 2}$. Increasing the number of amino acid residues that form hydrogen bond interactions in the QM
\end{abstract}


layer showed significant impact in binding interaction energy differences and the binding stabilities of the carbapenems inside the active pocket of $\mathrm{Ldt}_{\mathrm{Mt} 2}$. The theoretical binding free energies obtained in this study reflect the same trend of the experimental results. The electrostatic, hydrogen bond and Van der Waals interactions between the carbapenems and $\mathrm{Ldt}_{\mathrm{Mt} 2}$ were also assessed. To further examine the nature of intermolecular interactions for carbapenem- $\mathrm{Ldt}_{\mathrm{Mt} 2}$ complexes, AIM and NBO analysis were performed for the QM region (carbapenems and the active residues of $\mathrm{Ldt}_{\mathrm{Mt} 2}$ ) of the complexes. These analyses revealed that the hydrogen bond interactions and charge transfer from the bonding to anti-bonding orbitals enhances the binding and stability of carbapenem- $\mathrm{Ldt}_{\mathrm{Mt} 2}$ complexes.

\section{Graphical abstract}

The two-layered ONIOM (B3LYP/6-31+G(d): Amber) model was used to evaluate the efficacy of FDA approved carbapenems antibiotics towards $\mathrm{Ldt}_{\mathrm{Mt2}}$.

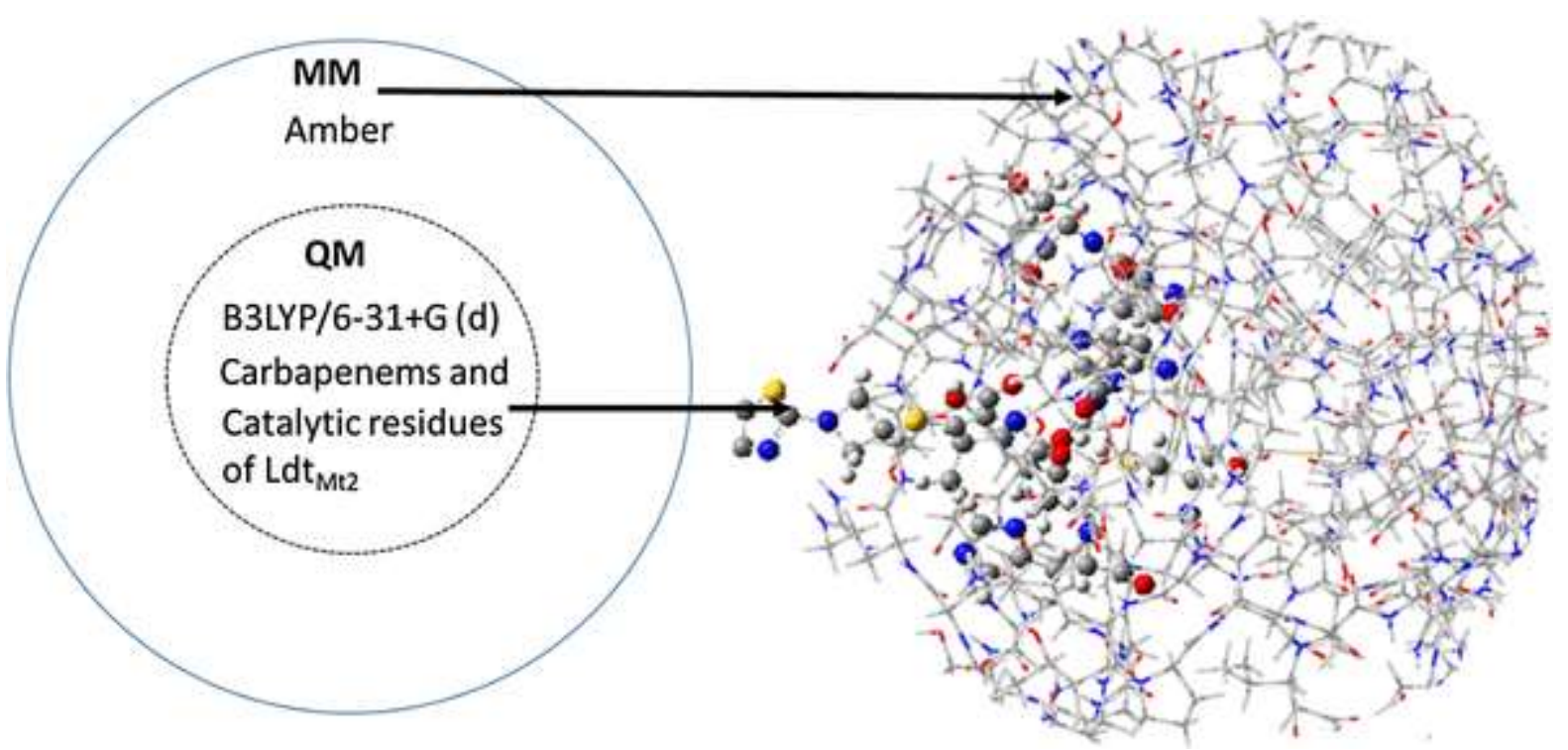

Keywords: Tuberculosis (TB); Mycobacterium tuberculosis (M. tuberculosis); L, Dtranspeptidase 2 (Ldt $\left.\mathrm{Mt}_{2}\right)$; Carbapenems; Our Own N-layered Integrated Molecular Orbital and Molecular Mechanics (ONIOM); Quantum theory of atoms in molecules (QTAIM); Natural bond orbital (NBO).

\section{Introduction}

Tuberculosis is an infectious disease caused by Mycobacterium tuberculosis (M. tuberculosis) bacilli that threatens many lives worldwide. Despite the advanced efforts made to improve TB treatment, the eradication of the disease is still an enormous challenge. Recent statistics from 
the World Health Organisation (WHO) reveal that about 10.4 million new TB cases were reported in $2016^{1}$. The growing incidences of multi-drug resistant (MDR-TB) and extensively drug-resistant (XDR-TB) strains of $M$. tuberculosis complicates the treatment regimens currently available thus threatening a return to a pre-antibiotic era ${ }^{2,3}$.

The upsurge of resistance to currently available anti-TB therapeutics leads to rapid dissemination of the infection. In South Africa, the incident cases of MDR and XDR continue to be a leading burden to public health care, as the disease remains the foremost cause of death ${ }^{4}$. For HIV patients, South Africa has the highest TB burden amongst 22 Sub-Saharan countries and has the highest figures of HIV-infected people suffering from TB, which contributes to high incidence cases of multi-drug resistant tuberculosis ${ }^{5}$. In the light of this fact, development of novel anti-tubercular therapeutic agents is urgently required ${ }^{6}$.

The peptidoglycan moiety of $M$. tuberculosis involves $4 \rightarrow 3$ and $3 \rightarrow 3$ peptide cross-links facilitated by D, D-transpeptidase and L, D-transpeptidase (LDT) enzymes, respectively. Disruption of peptidoglycan biosynthesis and cross-linking requires complete inhibition of both transpeptidases which subsequently kills the bacteria ${ }^{6,7}$. Most bacterial species possess approximately less than $10 \%$ of $3 \rightarrow 3$ cross-linkages catalysed by LDTs during the exponential and stationary phase of growth. M. tuberculosis is the only known Mycobacterium that demonstrates a high content of $3 \rightarrow 3$ crosslinks ( $80 \%$ ) making this enzyme family an attractive $\operatorname{target}^{8-10}$.

Carbapenems are a well-known class of $\beta$-lactam antimicrobial agents with reported inhibitory properties against different transpeptidases ${ }^{8,11,12}$. In particular, carbapenem derivatives are known as effective compounds against L, D-transpeptidase 2 from M. $_{\text {tuberculosis }}{ }^{8,9}$. This enzyme has thus been identified by various researchers as a possible target for TB inhibition" 10, 13-17. Erdemli et al., ${ }^{9}$ established that L, D-transpeptidase 2 ( $\left.\mathrm{Ldt}_{\mathrm{Mt} 2}\right)$, is the product of gene MT2594 in Mtb. A M. tuberculosis strain lacking Ldt $_{\mathrm{Mt} 2}$ leads to alteration of colony morphology, loss of virulence and enhanced susceptibility to amoxicillin-clavulanate during the chronic phase of infection. Therefore, $\mathrm{Ldt}_{\mathrm{Mt} 2}$ is vital for the physiology of the peptidoglycan and is essential for the virulence of $M$. tuberculosis ${ }^{6,9,18}$. Catalysis occurs at the active site (residues Cys354, His336, and Ser337) of Ldt $\mathrm{Mt}_{2}$ and involves two reaction steps namely, acylation and deacylation ${ }^{9}$. In this proposed mechanism, a proton (R-SH) transfer occurs from Cys354 to the His336 followed by a nucleophilic attack (R-S $\left.{ }^{-}\right)$on the carbonyl group of the substrate by the sulfur of Cys354. However, the presence of His352 and Asn356 
residues provides the possibility of hydrogen bond formation and hydrophobic interactions which can stabilize the enzyme-inhibitor complex. The carbapenems' thio-side chain can also be potentially tailored to accommodate the protein surface and to optimize inhibition of $\mathrm{Ldt}_{\mathrm{Mt} 2}$. In addition, earlier experimental observations reconfirmed that the thio-side chain of the carbapenem derivatives fulfils an important role to optimize the inhibitor efficiency by forming critical hydrogen bonds inside the active site pocket ${ }^{18}$.

Besides several publications in the field of computer-aided drug discovery for the potential anti-HIV agents made by our research group ${ }^{19-21}$, the theoretical binding free energies of the commercially available inhibitors against Ldt $\mathrm{Mt}_{2}$ were also reported using MM-GBSA and solvation interaction energy (SIE) methods ${ }^{22}$. The role of $\operatorname{Ldt}_{\mathrm{Mt} 2}$ flap opening and closing upon complexation of the substrate and three carbapenems, namely: ertapenem, imipenem and meropenem, was also reported using $140 \mathrm{~ns}$ molecular dynamics simulation with explicit water solvent ${ }^{23}$. The determined binding affinities showed more favorable free binding energies for ertapenem and meropenem than imipenem in the closed conformation of the $\beta$-hairpin flap ${ }^{23}$. Despite several studies in this field, to the best of our knowledge, limited attention has been paid to the inhibition mechanism of $\mathrm{Ldt}_{\mathrm{Mt} 2}$ using carbapenem derivatives.

The n-layered integrated molecular orbital and molecular mechanics (ONIOM) $)^{24-28}$ method is a hybrid QM/MM technique used to compute interaction energies using the combination of quantum mechanical method $(\mathrm{QM})$ with a molecular mechanics $(\mathrm{MM})$ force field ${ }^{29,30}$. This multi-layered method is utilized mostly in large biosystems where the model and real system are consistently treated with accurate level of theories ${ }^{24-28}$. In this approach, the active residues and ligand are treated with a high level of theory (Density Functional Theory or ab initio) while

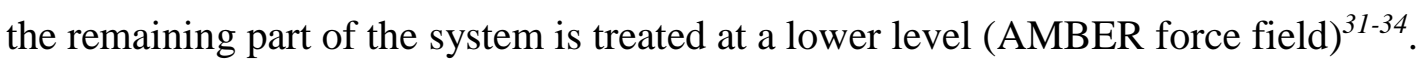

In this study, the molecular orbital calculations were performed for four selected FDAapproved carbapenems (biapenem, imipenem, meropenem, and tebipenem abbreviated as Bia, Imi-, Mero- and Tebi-, respectively) complexed to $\mathrm{Ldt}_{\mathrm{Mt} 2}$ using a two-layer ONIOM (QM:MM) approach. Structures of the carbapenems for the present work are presented in Figure 1. 


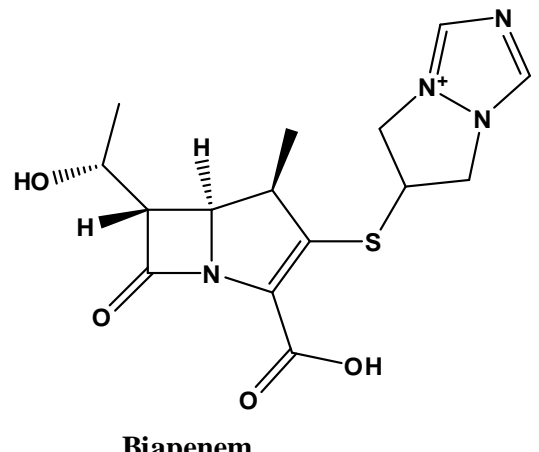

Biapenem

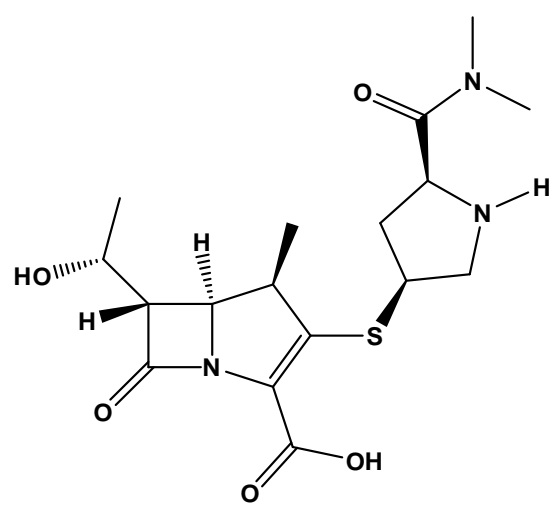

Meropenem
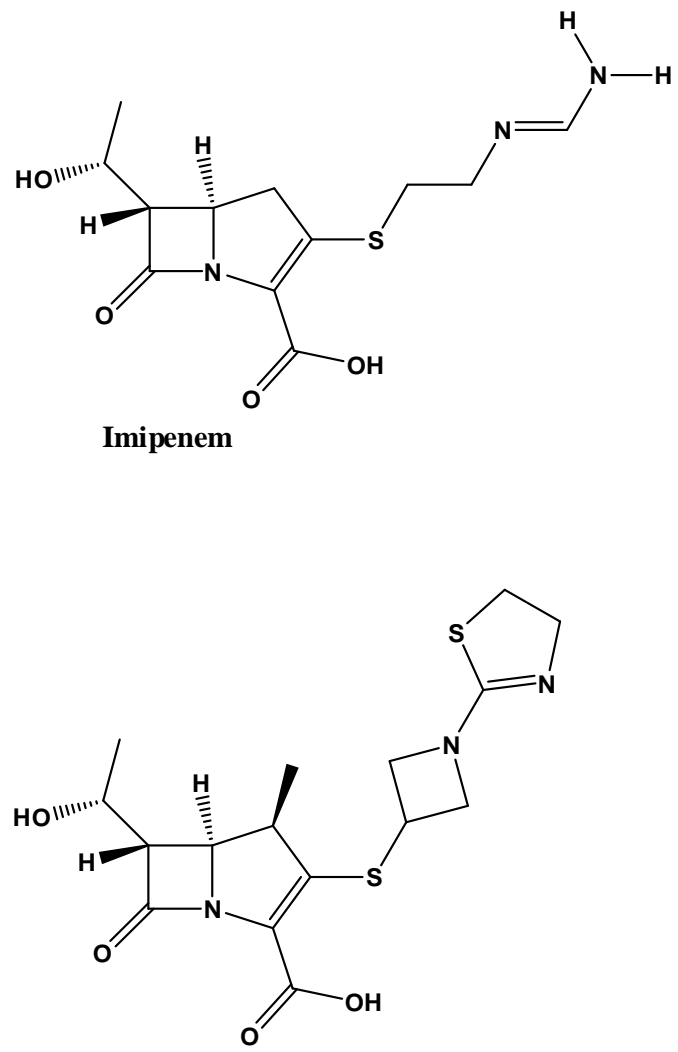

Tebipenem

Figure 1. The structures of the selected FDA approved carbapenems that are active against L, D transpeptidase 2 .

For further analysis of the calculated ONIOM binding free energies, we investigated the electrostatic and hydrogen bonding interactions for these inhibitor-enzyme complexes. For further analysis of the intermolecular interactions between $\operatorname{Ldt}_{\mathrm{Mt} 2}$ and the selected carbapenems, QTAIM ${ }^{35}$ and $\mathrm{NBO}^{36}$ analysis were performed on the QM region of the biosystems (carbapenems and the active residues of $\mathrm{Ldt}_{\mathrm{Mt} 2}$ ). The AIM topological indices assessed the nature of hydrogen bond interactions through molecular orbital interactions and NBO analysis determined the electron charge transfer between carbapenems and the active residues of $\mathrm{Ldt}_{\mathrm{Mt} 2}$. Our hypothesis is that this computational study will provide a greater level of insight into the crucial interactions of the inhibitor during complexation. This in turn, will be useful for the design of novel and more potent anti-TB drugs from carbapenem inhibitors.

\section{Material and Methods}

\section{System preparation}

The enzyme-inhibitor complex structures of $M$. tuberculosis Ldt $_{\mathrm{Mt} 2}$ were prepared by superimposing Chain A of $3 \mathrm{TUR}^{9}$ complexed with the natural substrate and $3 \mathrm{VYP}^{37}$ meropenem-bound complex. The covalently bound meropenem (PDB code: 3VYP) was 
restored by deletion of the covalent bond between the sulfur atom of cysteine residue and the carbonyl carbon of $\beta$-lactam ring. The $\beta$-lactam ring was refined, and the hydrogen atoms were added and optimized. This complexed structure (Mero- $-\mathrm{Ldt}_{\mathrm{Mt} 2}$ ) was then used as a reference to model other $\mathrm{Bia}-\mathrm{Ldt}_{\mathrm{Mt} 2}$, Imi- $\mathrm{Ldt}_{\mathrm{Mt} 2}$ and $\mathrm{Tebi}-\mathrm{Ldt}_{\mathrm{Mt} 2}$ complexes by superimposing other inhibitors into the same geometry using PyMOL ${ }^{38}$. The superimposed 3D structures of 3TUR ( Ldt $_{\mathrm{Mt} 2}$ in complex with peptidoglycan fragment as natural substrate) and 3VYP (meropenem-Ldt $\mathrm{Mt}_{2}$ adduct), as well as other aligned complexes are presented in Figures $1 S$ and $\mathbf{2 S}$ (Supplementary material).

The X-leap ${ }^{39}$ software was used on the starting complex to affix the missing protons. The MM parm99 force field ${ }^{40}$ (ff99SB) was used for proteins and GAFF $^{41}$ was used for the inhibitors. The complexes were solvated with TIP $3 \mathrm{P}^{42}$ explicit water in a cubic box with $10 \AA$ distance and counterions were added to neutralize the complexes. Partial Mesh Ewald (PME) ${ }^{43}$ method was applied for long range electrostatic forces with cut-off of $12 \AA$. All bonds to hydrogen atoms was constrained using the SHAKE algorithm. ${ }^{44}$ Two-stage geometric minimization was performed by 2500 steps of steepest decent minimization followed by 2500 of conjugated gradient to remove clashes and bad contacts. To accurately assign the protonation states of the residues in the enzyme at $\mathrm{pH}=7.8$, the empirical PropKa web server ${ }^{45}$ was used.

The prepared complexes were then subjected for ONIOM ${ }^{24-28}$ calculations. The ONIOM input files together with the optimized output files of all complexes are provided in PDB format with the supplementary materials.

\section{ONIOM hybrid (QM:MM) method}

All the calculations were performed using the Gaussian0 $0{ }^{46}$ program. It was established in numerous studies ${ }^{47-49}$ that the Becke3LYP ${ }^{51,52}$ functional yields energies in good agreement with high-level $a b$ initio methods. The accuracy of B3LYP 50 , 51 functionals produce significantly remarkable results for organic molecules ${ }^{50}$. The two-layered $\mathrm{ONIOM}^{24,25,52}$ hybrid approach (B3LYP/6-31+G (d): AMBER) invented by Morokuma et al., ${ }^{29}$ was employed to assess the binding affinities within the selected carbapenem-Ldt $\mathrm{Mt}_{2}$ complexes. In this ONIOM $^{24-28}$ model, the catalytic active residues of the Ldt Mt2 $_{2}$ enzyme (His336, Ser337 and Cys354 denoted as His187, Ser188 and Cys205 in this study) and the selected FDA-approved inhibitors were modeled using density functional theory (DFT $)^{53,54}, \mathrm{~B} 3 \mathrm{LYP}^{50,51}$ functional and the $6-31+\mathrm{G}(\mathrm{d})^{55,56}$ basis set. The remaining part of the enzyme was kept at the low level of theory $(\mathrm{MM})^{26,57}$ with an AMBER force field. 
A full geometry optimization was performed for the selected carbapenem-Ldt ${ }_{\mathrm{Mt} 2}$ complexes. Normal mode frequency analyses were performed at the same level of theory to examine the nature of stationary points to be in real minimum potential energy surface with no negative frequency. The total interaction energies are defined as:

$$
\Delta E_{\text {ONIOM }}=\Delta E_{\text {model,high }}+\Delta E_{\text {real,low }}-\Delta E_{\text {model,low }}
$$

Where, $\Delta E_{\text {model }}$ denote the energies of the model system defined at high and low level of theory and $\Delta E_{\text {real }}$ denote the whole (real) system. Thus, the equivalent binding interaction ONIOM energies of the complex systems are determined as follows:

$$
\Delta G_{\text {ONIOM }} \approx \Delta G=G_{\text {carbapenem-LdtMt2 }}-\left(G_{\text {carbapenem }}+G_{\text {LdtMt2 }}\right)
$$

The thermodynamic quantities (enthalpies and entropies and it different entropic contributions) were also attained from frequency calculations. The different entropic contributions (rotation, translation, and vibration) for carbapenem-Ldt $\mathrm{Mt}_{2}$ complexes were calculated as follows:

$$
\Delta S_{\text {total }}=\Delta S_{\text {carbapenem }- \text { LdtMt2 }}-\left(\Delta S_{\text {carbapenems }}+\Delta S_{\text {LdtMt2 }}\right)
$$

\section{Mode of interactions and hydrogen-bond analysis}

The LigPlot ${ }^{58}$ program generated the 2-D representation of protein-ligand complexes from the output file of the PDB input file. This program gives an informative representation of intermolecular interactions (hydrogen bond and hydrophobic interactions) that exist between the protein and the ligand. The hydrogen bonds ${ }^{59-61}$ and hydrophobic interactions for four selected carbapenem- $\mathrm{Ldt}_{\mathrm{Mt} 2}$ complexes were analysed using LigPlot ${ }^{58}$. The hydrogen bond distances between the carbapenems and $\mathrm{Ldt}_{\mathrm{Mt} 2}$ in the complexes were determined using Discovery Studio $^{62}$ to attain the proximity of cysteine towards the $\beta$-lactam's carbonyl group. This is essential for determining the binding mode of carbapenems interacting with $\mathrm{Ldt}_{\mathrm{Mt} 2}$ and to provide the best inhibitor pose relative to the catalytic residues.

\section{QTAIM calculations}

The quantum theory of atoms in molecules (QTAIM) invented by Bader $^{63}$ is a theoretical tool that enables hydrogen bond analysis. The hydrogen bonds (HB) interactions between a hydrogen donor and acceptor groups are connected by a Bond Critical Point (BCP). The basis of the theory is fundamentally reliant on the critical points (CPs) of the molecular electronic charge density $\rho(\mathrm{r})$. The critical points are described by three eigenvalues of Hessian matrix 
$\left(\lambda_{1}, \lambda_{2}\right.$, and $\left.\lambda_{3}\right)$ based on the molecular electronic charge densities. Popelier and $\operatorname{Bader}^{64}$ used the AIM analysis to characterize the significance of chemical interactions that strictly involves the hydrogen bonding between clustered systems ${ }^{64}$. The two measures are proposed, electron density $\rho(\mathrm{r})$ and the Laplacian of the electron density $\nabla^{2} \rho(\mathrm{r})$, assessed at the BCP of two hydrogen bonded atoms. The location of BCP strongly relies on the electronegativities of the interacting atoms in molecules. Another important parameter is the bond ellipticity $(\varepsilon)$, defined as follows:

$\varepsilon=\left[\left(\frac{\lambda_{1}}{\lambda_{2}}\right)-1\right]$

Where $\lambda_{1}$ and $\lambda_{2}$ are perpendicular curvatures of the density at the BCP described by the large values of electron density. The ellipticity $(\varepsilon)$ provides a significant measure of $\pi$-bond nature and delocalization of the electronic charge and determines the bond stability.

\section{Natural bond orbital (NBO)}

The natural bond orbital (NBO) analysis ${ }^{36}$ is an appropriate method used to study the effect of electron charge transfer between $\mathrm{QM}$ region of $\mathrm{Ldt}_{\mathrm{Mt} 2}$ and carbapenems using the second perturbation theory of NBO analysis using NBO3.1 program implemented in Gaussian 09 software ${ }^{46}$. The NBO analysis was achieved based on the molecular wave functions distorted into one-centre (lone pair) and two centres (bond) representations. The Fock matrix diagonal elements in the NBO depiction represent the energies for localized bonds, lone pairs, and antibonds of the studied systems. The stabilization energy $E^{(2)}$ associated with $i \rightarrow j$ delocalization is explicitly estimated by the following equation:

$E^{(2)}=\Delta E i j=q i \frac{F(i, j)^{2}}{\varepsilon_{j}-\varepsilon_{i}}$

Where $q_{i}$ denotes the $i$ th donor orbital occupancy, $\varepsilon_{i}$, and $\varepsilon_{j}$ are the diagonal elements (orbital energies) and $F(i, j)$ is the off-diagonal element, respectively, associated with the NBO Fock matrix. The higher the value of $E^{(2)}$, the more charge transfer between electron donors and electron acceptors ${ }^{36}$. 


\section{Results and Discussion}

During geometry optimization it was observed that the carbapenems experienced slight movement inside the binding site of $\mathrm{Ldt}_{\mathrm{Mt} 2}$ (Figure 2) as expected ${ }^{22}$. The short-range distances between the sulfur atom of the catalytic cysteine residue and the carbonyl carbon of the $\beta$ lactam ring of the carbapenem were in the range of $3.6 \AA$ to $3.9 \AA$.

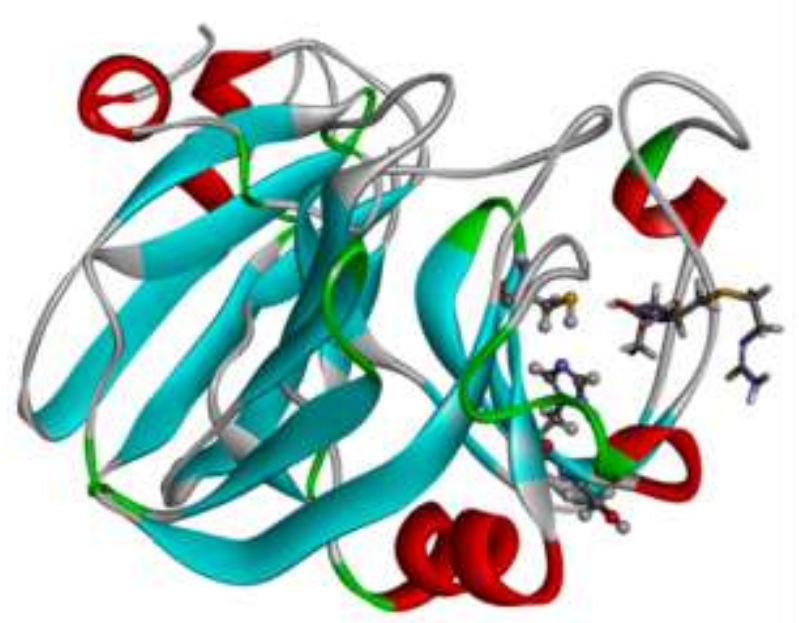

A

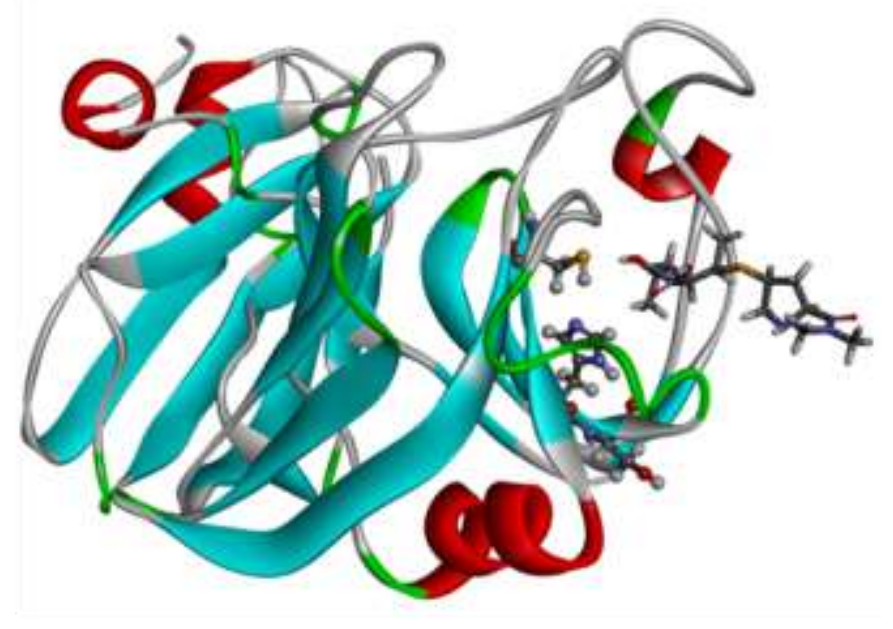

B

Figure 2. 3D-structure of $\mathbf{A}$. Imi- $\mathrm{Ldt}_{\mathrm{Mt} 2}$ and $\mathbf{B}$. Mero- $\mathrm{Ldt}_{\mathrm{Mt} 2}$ complexes, the inhibitor is presented as wireframe and the considered active pocket residues as ball and stick (Figure 3S). The ONIOM (Gaussian) input files as well as the optimized output files of all inhibitor-enzyme complexes are provided with the supplementary material.

\section{ONIOM interaction energies}

A descriptive illustration of our ONIOM model is shown in Figure 3, where the carbapenems and the catalytic residues of $\mathrm{Ldt}_{\mathrm{Mt} 2}$ were treated at QM (B3LYP/6-31+G(d)) level and the remaining part of the complexes was treated at MM level (AMBER force field). 


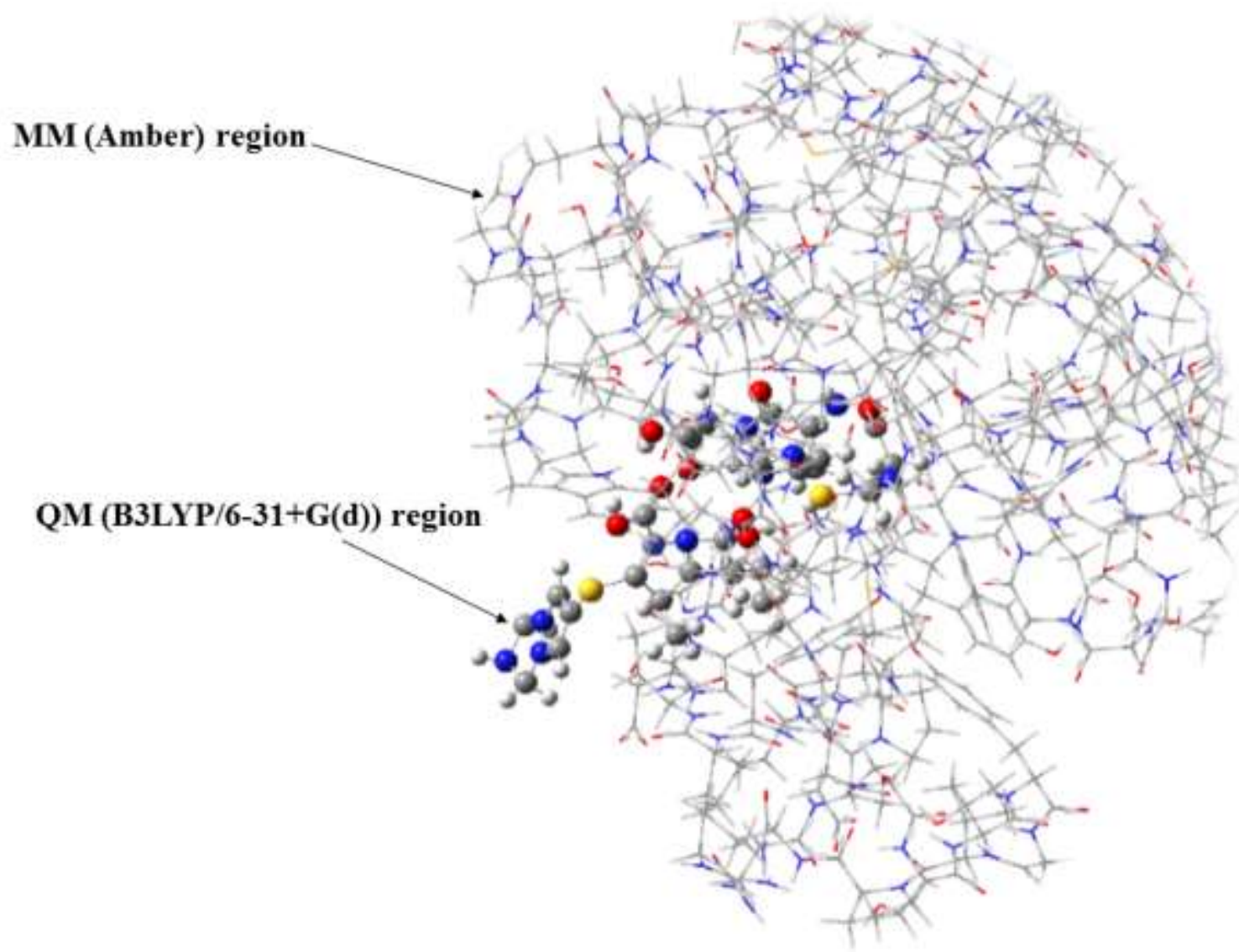

Figure 3. A two-layered QM:MM ONIOM (B3LYP/6-31G+(d): AMBER) model of Bia-Ldt complex. Active site residues [His336 (187), Ser337 (188) and Cys354 (205)] were also treated at the same QM level (Figure 4S). The ONIOM (Gaussian) input files as well as the optimized output files of all inhibitor-enzyme complexes are also provided with the supplementary material.

To assess the binding affinities of the selected carbapenems against Ldt $_{\mathrm{Mt} 2}$ using the ONIOM method, we included the three catalytic triad residues [His336 (187), Ser337 (188), Cys354 (205)] of Ldt Mt2 $_{2}$ and carbapenems at QM level of theory (Table 1). After that, two more residues (His203 and Asn207), found to be in close contact with the carbapenems, were also included at the QM level (Table 1S) to ascertain the fundamental role they have in thermodynamic properties.

As for the comparison of our two applied ONIOM models, the first model with three active site residues [His336 (187), Ser337 (188) and Cys354 (205)] treated at the QM level of theory exhibited less negative theoretical binding free energies (Table 1) in comparison to the second model with five active site residues [His336 (187), Ser337 (188), His352 (203), Cys354 (205) and Asn356 (207)] (Table 1S). 
The fist model followed the experimental trend ${ }^{9,65}$, while the second model, with five catalytic residues at the QM level, the binding energy trend for tebipenem and imipenem was reversed (Table 1S).

The selected carbapenems possess a common thiol-group with varying side chains that distinguish them from each other. The side chains are said to play an integral role in stabilizing the complex by forming electrostatic and van der Waals interactions during the binding process.

Table 1. The binding free energies $\left(\mathrm{kcal} \mathrm{mol}^{-1}\right)$ for FDA-approved carbapenem- $\mathrm{Ldt}_{\mathrm{Mt} 2}$ complexes evaluated using ONIOM (B3LYP/6-31+G (d): AMBER). [reported experimental data ${ }^{9}, 65$ and calculated theoretical results]. Note: catalytic residues [His336 (187), Ser337 (188) and Cys354 (205)] are considered at high level.

\begin{tabular}{|c|c|c|c|c|c|c|c|}
\hline Complexes & $\begin{array}{c}\Delta G_{\text {bind }}(\operatorname{Exp}) \\
\text { kcal mol }^{-1}\end{array}$ & $\begin{array}{c}\Delta G_{\text {bind }}(\text { Calc }) \\
\text { kcal mol }^{-1}\end{array}$ & $\begin{array}{c}\qquad H \\
\qquad \mathrm{kcal} \mathrm{mol}^{-1}\end{array}$ & $\begin{array}{c}\quad \Delta S_{\text {Total }} \\
\text { cal } \text { mol }^{-1} \mathbf{K}^{-1}\end{array}$ & $\begin{array}{c}\quad \Delta S_{\text {trans }} \\
\text { cal } \mathrm{mol}^{-1} \mathbf{K}^{-1}\end{array}$ & $\begin{array}{c}\Delta S_{\text {rot }} \\
\text { cal } \mathrm{mol}^{-1} \mathrm{~K}^{-1}\end{array}$ & $\begin{array}{c}\quad \Delta S_{\text {vib }} \\
\text { cal } \mathrm{mol}^{-1} \mathrm{~K}^{-1}\end{array}$ \\
\hline $\mathrm{Imi}-\mathrm{Ldt}_{\mathrm{Mt} 2}$ & -9.8 & -23.9 & -43.6 & -66.1 & -43.0 & -34.8 & 11.7 \\
\hline Tebi- $\mathrm{Ldt}_{\mathrm{Mt} 2}$ & -9.4 & -23.8 & -42.5 & -62.7 & -43.7 & -36.3 & 17.3 \\
\hline $\mathrm{Bia}-\mathrm{Ldt}_{\mathrm{Mt} 2}$ & -9.0 & -23.2 & -44.1 & -70.0 & -43.4 & -35.5 & 8.9 \\
\hline Mero- $\mathrm{Ldt}_{\mathrm{Mt} 2}$ & -8.2 & -14.9 & -41.9 & -91.6 & -43.7 & -36.0 & -12.0 \\
\hline
\end{tabular}

Gibb's free energy $(\Delta \boldsymbol{G})$, Enthalpies $(\Delta \boldsymbol{H})$, Entropies $(\Delta S)$ and entropic contribution, translational $\left(\Delta \boldsymbol{S}_{\text {trans }}\right)$, rotational $\left(\Delta S_{\text {rot }}\right)$, vibrational $\left(\Delta S_{\text {vib }}\right)$ are derived from equations 2 and 3 . The ONIOM (Gaussian) input files as well as the optimized output files of all inhibitor-enzyme complexes are also provided with the supplementary material. (ONIOM calculations were carried out at default temperature of $298.15 \mathrm{~K}$ )

Our group previously reported a longer MD (140 ns) simulation study that aimed to investigate the role of flap dynamics during the binding process of the natural substrate as well as three carbapenems $^{23}$. Their results for the carbapenem- $\mathrm{Ldt}_{\mathrm{Mt} 2}$ complexes, namely; Mero- $\mathrm{Ldt}_{\mathrm{Mt} 2}$, Erta- $\mathrm{Ldt}_{\mathrm{Mt} 2}$, and Imi- $\mathrm{Ldt}_{\mathrm{Mt} 2}$ gave binding free energies $\left(\Delta G_{\text {bind }}\right)$ of; $-40.4 \mathrm{kcal} \mathrm{mol}^{-1},-38.0$ $\mathrm{kcal} \mathrm{mol}^{-1}$ and $-34.5 \mathrm{kcal} \mathrm{mol}^{-1}$, respectively ${ }^{23}$. In contrast to that, the experimental binding energy trend for Mero- $\mathrm{Ldt}_{\mathrm{Mt} 2}$ and Imi-Ldt $\mathrm{Mt}_{2}$ is reversed (there is no reported value for ertapenem). Therefore, to further improve the model for these inhibitor-enzyme complexes, a hybrid two layered ONIOM approach was chosen to explore the non-covalent binding interaction energies as another method to investigate the pre-complex stability prior to carbapenems binding.

The theoretical Gibb's free energies $(\Delta G)$ for carbapenem- $\mathrm{Ldt}_{\mathrm{Mt} 2}$ complexes range from -23.9 to $-14.9 \mathrm{kcal} \mathrm{mol}^{-1}$. However, Imi- $\mathrm{Ldt}_{\mathrm{Mt} 2}$, Tebi- $\mathrm{Ldt}_{\mathrm{Mt} 2}$ and Bia- $\mathrm{Ldt}_{\mathrm{Mt} 2}$ have comparable 
Gibb's free energies $\Delta G\left(-23.9 \mathrm{kcal} \mathrm{mol}^{-1},-23.8 \mathrm{kcal} \mathrm{mol}^{-1}\right.$ and $-23.2 \mathrm{kcal} \mathrm{mol}^{-1}$, respectively) with a discrepancy of $0.08-0.7 \mathrm{kcal} \mathrm{mol}^{-1}$ and the relative energy differences are in good agreement with experimental data ${ }^{9,} 65$ (Table 1). Even though Mero- Ldt $_{\text {Mt2 }}$ complex shows the weakest binding energy for both experimental and theoretical results, the calculated theoretical result displays larger relative differences compared to the experimental results ${ }^{9,65}$.

The enthalpy contribution $(\Delta H)$ for carbapenem - $\mathrm{Ldt}_{\mathrm{Mt} 2}$ complexes ranges from -44.1 to -41.9 $\mathrm{kcal} \mathrm{mol}^{-1}$. This indicates that the non-covalent complexation process is exothermic. The enthalpy contribution $(\Delta H)$ of Bia-Ldt ${ }_{\mathrm{Mt} 2}$ and Imi-Ldt $\mathrm{Mt}_{2}$ complexes is $-44.1 \mathrm{kcal} \mathrm{mol}^{-1}$ and $43.6 \mathrm{kcal} \mathrm{mol}^{-1}$ respectively and are comparable. Finally, the Mero- $-\mathrm{Ldt}_{\mathrm{Mt} 2}$ complex has the weakest enthalpy contribution of $\Delta H=-41.9 \mathrm{kcal} \mathrm{mol}^{-1}$, which contributes to the weak calculated binding free energy $\left(\Delta G=-14.9 \mathrm{kcal} \mathrm{mol}^{-1}\right)$.

In the case of entropy contribution $(\Delta S)$, it was noted that Mero-Ldt ${ }_{\text {Mt2 } 2}$ shows the most negative entropy $\Delta S=-91.6 \mathrm{cal} \mathrm{mol}^{-1} \mathrm{~K}^{-1}$. The higher entropy signifies reduced degrees of freedom of the inhibitors in the protein active pocket. This contributes to the less favourable binding free energy for meropenem. Bia-Ldt $\mathrm{Lt}_{2}$ exhibits a negative entropy of $\Delta S=-70.0 \mathrm{cal} \mathrm{mol}^{-1} \mathrm{~K}^{-1}$, while that of Imi-Ldt $\mathrm{Mt}_{2}$ is $-66.1 \mathrm{cal} \mathrm{mol}^{-1} \mathrm{~K}^{-1}$ and Tebi-Ldt $\mathrm{Mt}_{2}$, with the most favourable entropy response at $-62.7 \mathrm{cal} \mathrm{mol}^{-1} \mathrm{~K}^{-1}$. This overcomes its smaller enthalpy value rendering it the second highest in Gibb's binding energy. Additionally, among the entropy components, the translational $\left(\Delta S_{\text {trans }}\right)$ and rotational $\left(\Delta S_{\text {rot }}\right)$ values for all considered complexes are in close range, while the vibrational entropies $\left(\Delta S_{\text {vib }}\right)$ differs significantly in all complexes and this could be attributed to the thio-side chain of each considered carbapenem. Mero- $\mathrm{Ldt}_{\mathrm{Mt} 2}$ is the only complex that displays a negative vibrational entropy which contributes significantly to the overall entropy value.

\section{Hydrogen bonding interactions}

The fundamental role of hydrogen bonds in target-drug affinities has been significantly explored $^{59,66,67}$. Moreover, protein conformation is driven by hydrogen bond formation, which thus optimizes hydrophobic interactions and leads to increased binding affinities of complex molecules $^{59}$. The van der Waals and electrostatic interactions in complexes are crucial for maintaining stability between protein-ligand arrays. Hydrogen bond interactions serve a significant role in stabilizing the inhibitor inside the binding pocket although these are considered as weak interactions ${ }^{68}$. Structural analyses of the carbapenems show significant 


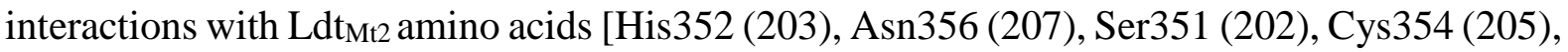
Thr350 (201), His336 (187), Thr320 (171), Trp340 (191), Ser341 (192), and Tyr318(169)] in the catalytic cavity. In most cases, the hydroxyethyl substituent, carbonyl oxygen, and nitrogen of the carbapenem $\beta$-lactam ring are responsible for hydrogen bond formation. In order to obtain more details and understanding of these interactions, the distances of hydrogen bonds between ligands and receptors were analysed with Discovery studio ${ }^{62}$ before and after optimization (Figure 4). The measured intermolecular bond distances, for all the selected carbapenem- $\mathrm{Ldt}_{\mathrm{Mt} 2}$ complexes, between the sulfur atom of the catalytic cysteine and carbonyl carbon of the $\beta$-lactam ring were adequately in proximity for nucleophilic attack as expected. It was observed that in all complexes, the average bond distance between the sulfur atom of cysteine and carbonyl carbon of the $\beta$-lactam ring had increased (after optimization) with a concomitant decrease in the distance from the hydroxyl hydrogen to the sulfur. As a result, the carbonyl oxygen also participated in forming hydrogen bonds with the His203 and Asn207. (See details shown in supplementary material Figure 5S).

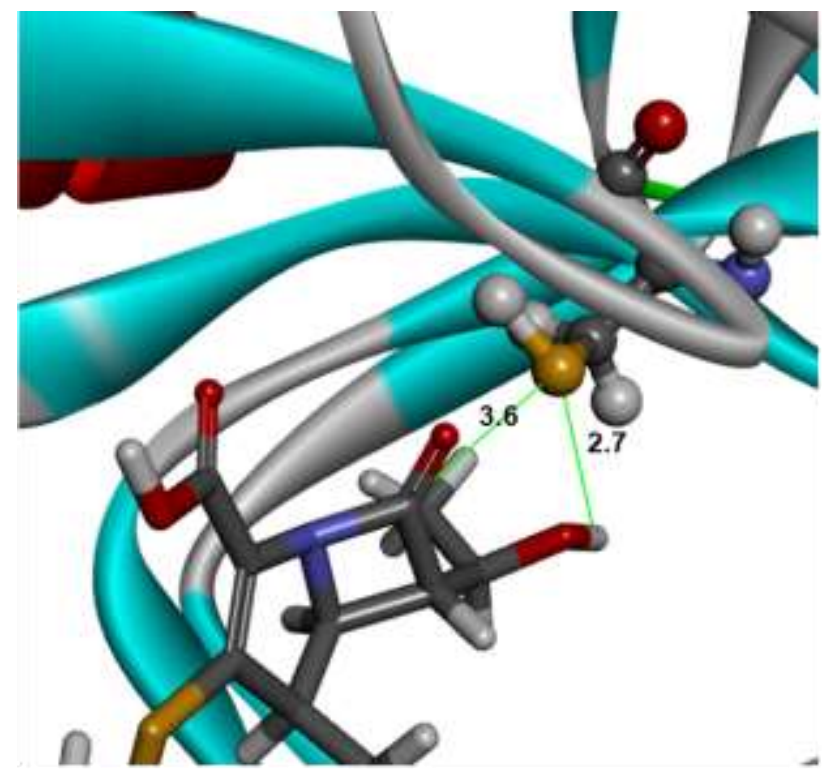

a

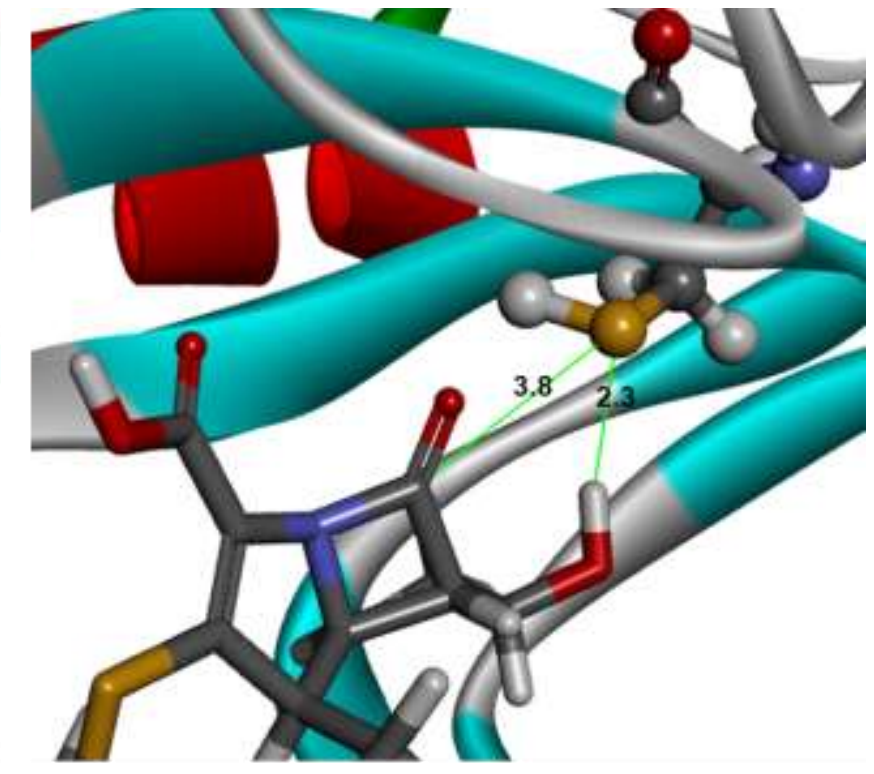

b

Figure 4. Schematic representation of hydrogen bond interactions and their respective distances in angstrom ( $)$. (A) Before optimization (B) After optimization. The ONIOM input files as well as the optimized output files of all inhibitor-enzyme complexes are also provided as PDB files with the supplementary material. 


\section{Hydrogen bond modes of interaction in carbapenem-LdtMt2 complexes}

To further examine the nature of the calculated binding free energies for the FDA approved inhibitors complexed with $\mathrm{Ldt}_{\mathrm{Mt} 2}$, the $\mathrm{LigPlot}^{58}$ program was used to reveal the possible intermolecular hydrogen bond and electrostatic interactions between the carbapenem-Ldt $\mathrm{Mt}_{2}$ complexes. The critical amino acid residues such as His203, Asn207, Ser202, Cys205, Thr201, His187, Thr171, Trp191, Ser192, and Tyr169, (These correspond to His352, Asn356, Ser351, Cys354, Thr350, His336, Thr320, Trp340, Ser341, and Tyr318 of the original crystal structure), directly interact with the inhibitor by forming hydrogen bonds and hydrophobic interactions (Figure 5). The details of other complexes are depicted in the supplementary materials (Figure 6S).

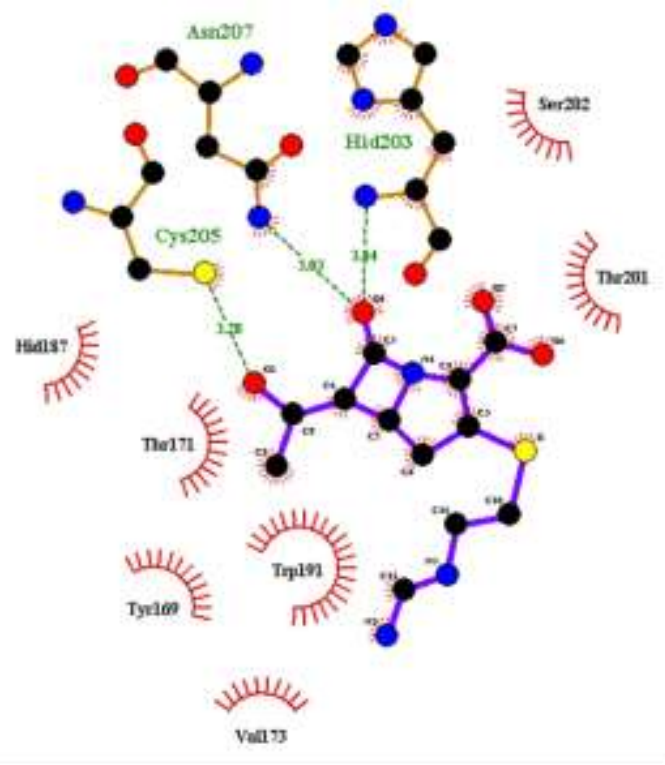

A

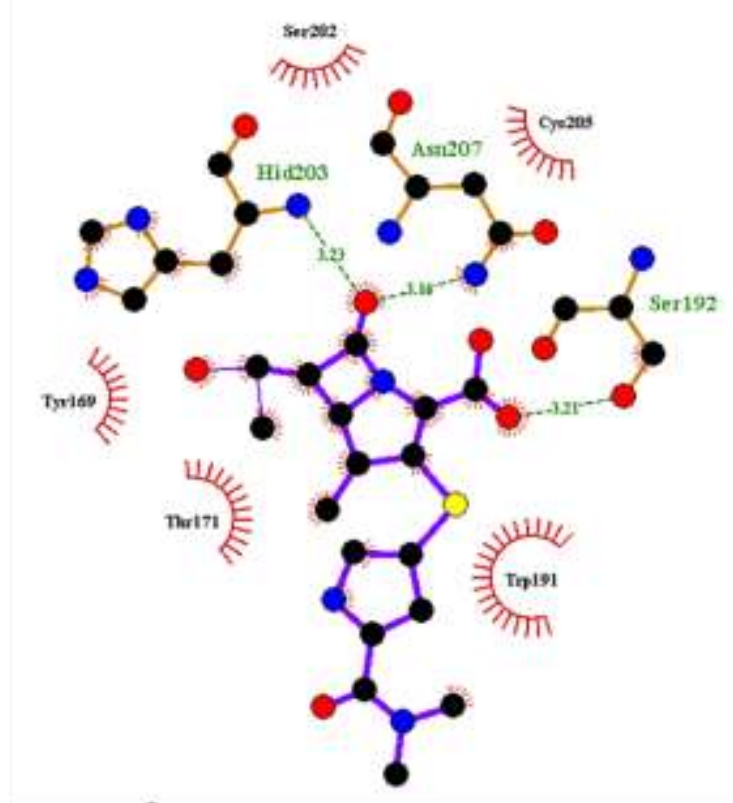

B

Key

The meaning of the items on the plot is as follows:

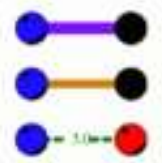

Ligand bond

Non-ligand bond

Hydrogen bond and its length

His 53 Non-ligand residues involved in hydrophobic

$\hat{x}$ in contact(s)

Corresponding atoms involved in hydrophobic contact(s)

Figure 5. A 2-D schematic representation of hydrogen bond and hydrophobic interactions between catalytic amino acid residues and the carbapenems (A. Imipenem and B. Meropenem). Green dotted lines represent hydrogen bond interactions.

The plots show hydrogen bonding and electrostatic interactions occurring between the inhibitors and the catalytic active site residues of $\mathrm{Ldt}_{\mathrm{Mt} 2}$. As it is observed, the arrangement of 
the catalytic amino acids residues displays a consistent pattern in proximity to the $\beta$-lactam ring of all the carbapenems.

\section{QTAIM analysis}

The quantum theory of atoms in molecules (QTAIM) has been used to characterize and quantify the H-bonding interactions for carbapenem-Ldt $\mathrm{Mt}_{2}$ complexes as described by Bader ${ }^{63}$, 69. After geometry optimization of the carbapenem-Ldt $\mathrm{Mt}_{2}$ complexes using a two-layered ONIOM (B3LYP/6-31G+(d): AMBER) model, the QM region of carbapenem-Ldt ${ }_{\mathrm{Mt} 2}$ complexes [catalytic triad residues: His336 (187), Ser337 (188), and Cys354 (205) and the selected carbapenems], were truncated and the wave functions of the QM region were calculated using B3LYP/6-31G+(d). Followed by the ab initio wave function calculations, the electron topography of carbapenem-Ldt Mt2 $_{2}$ complexes were generated using AIM2000 software package ${ }^{70}$. The topological analysis of the electron charge density provides the location of the critical points wherein the gradient of electron density is insignificant ${ }^{35}$. Thee bond critical point (BCP), which determine the existence or non-existence of hydrogen bond interactions $(\mathrm{HB})$ and the molecular graph to connect the bond paths of critical points of the studied truncated systems, were obtained. The Imi-Ldt $\mathrm{Mt}_{2}$ and Mero- $\mathrm{Ldt}_{\mathrm{Mt} 2}$ complexes are shown in Figure 6. In general, if a hydrogen bond does exist between two atoms, the range of $\rho(r)$ and $\nabla^{2} \rho(r)$ are between $0.002-0.035$ a.u. and 0.024-0.139 a.u., respectively ${ }^{71}$. The topological parameters for the truncated carbapenem- $\mathrm{Ldt}_{\mathrm{Mt} 2}$ complexes are tabulated in Table 2. For consistency, we have included the same interactions for all studied systems in the table, even if some of these do not represent a classical hydrogen bond.

According to Table 2, the $\rho(r)$ and $\nabla^{2} \rho(r)$ values for carbapenem- $\operatorname{Ldt}_{\mathrm{Mt} 2}$ complexes vary in terms of their respective interacting atoms at specific critical points $(\mathrm{CP})$. However, the minimum and maximum for both the $\rho(r)$ and $\nabla^{2} \rho(r)$ in all the studied carbapenem- Ldt $_{\mathrm{Mt} 2}$ complexes interactions are $0.0053-0.0245$ and $0.0184-0.0594$ a.u, respectively. In this regard, Imi-Ldt $\mathrm{Mt}_{2}$, Tebi- $\mathrm{Ldt}_{\mathrm{Mt} 2}$ and $\mathrm{Bia}-\mathrm{Ldt}_{\mathrm{Mt} 2}$ have comparable $\rho(r)$ and $\nabla^{2} \rho(r)$ values that determine the existence of hydrogen bond formation at each $\mathrm{BCP}$ and the strength of the hydrogen bond interactions, respectively, as represented by red dots in the molecular graph plot (Figure 6.). It is noteworthy that the average values for $\rho(r)$ and $\nabla^{2} \rho(r)$ of HB's for each complex also corresponds to the theoretical and experimental Gibb's binding free energies.

The Laplacian of charge density at the bond critical point, $\nabla^{2} \rho(r)$, is defined as the sum of three preliminary curvatures of the function at each point of the space. The sign of $\nabla^{2} \rho(r)$ serves an 
integral role in the determination of whether the charge density is locally depleted $\nabla^{2} \rho(r)>0$, or locally concentrated $\nabla^{2} \rho(r)<0$. Consequently, the two topological parameters, the total kinetic energy $H(r)$ and the Laplacian $\nabla^{2} \rho(r)$ at specific BCP's, are often used to classify and characterize hydrogen bonds. It should be declared that the standard measures of hydrogen bonds are characterized by total electron energy density $H(r)<0$ and $\nabla^{2} \rho(r)<0$ for strong hydrogen bonds, whereas the medium hydrogen bonds with total electron energy density $H(r)<0$ and $\nabla^{2} \rho(r)>0$, and $H(r)>0$, and $\nabla^{2} \rho(r)>0$ are determined to be the weak ones ${ }^{72}$. The observed phenomena in the case of $\nabla^{2} \rho(r)$ values in Table 2 appear positive while some of the values of $H(r)$ appear negative. This indicates that the bond nature is considered as being partially covalent-partially electrostatic $(\mathrm{Pc}-\mathrm{Pe})^{73}$. The two parameters, $\nabla^{2} \rho(r)$ and $H(r)$ at $\mathrm{BCP}$ are normally used to categorize and characterize hydrogen bonds. Distance analysis is another crucial factor in determining the bond strength between interacting atoms induced by electronegativity because of electron charge density.

Table 2. AIM topological parameters including electron density ( $\boldsymbol{\rho})$ and their Laplacian of electron density $\left(\nabla^{2} \boldsymbol{\rho}\right)$ in a.u. and energetic parameters $\boldsymbol{G}(\boldsymbol{r}), \boldsymbol{H}(\boldsymbol{r})$, and $\boldsymbol{V}(\boldsymbol{r})$ in $(\mathrm{kcal} / \mathrm{mol})$ in carbapenem-Ldt $\mathrm{Mt}_{2}$ complexes calculated at the B3LYP/6-31+G(d).

\begin{tabular}{|c|c|c|c|c|c|c|c|}
\hline $\begin{array}{l}\text { Hydrogen } \\
\text { bonds }\end{array}$ & $\begin{array}{l}\text { Complexes } \\
\text { interactions }\end{array}$ & $\rho(r)$ & $\nabla^{2} \rho(r)$ & $G(r)$ & $H(r)$ & $V(r)$ & Ellipticity ( $(\varepsilon)$ \\
\hline & Imi-Ldt $_{\mathrm{Mt} 2}$ & & & & & & \\
\hline HB1 & $\mathrm{O}_{56} \mathrm{H} \cdots \mathrm{S}_{36}$ & 0.0232 & 0.0574 & 0.0154 & 0.0010 & 0.0164 & 0.0359 \\
\hline \multirow[t]{2}{*}{ HB2 } & $\mathrm{C}_{55} \mathrm{H} \cdots \mathrm{C}_{11}$ & 0.0053 & 0.0184 & 0.0034 & -0.0012 & 0.0022 & 0.6362 \\
\hline & Tebi-Ldt ${ }_{M t 2}$ & & & & & & \\
\hline HB1 & $\mathrm{O}_{81} \mathrm{H} \cdots \mathrm{S}_{36}$ & 0.0230 & 0.0565 & 0.0151 & 0.0010 & 0.0161 & 0.0370 \\
\hline \multirow[t]{2}{*}{ HB2 } & $\mathrm{C}_{80} \mathrm{H} \cdots \mathrm{C}_{11}$ & 0.0069 & 0.0233 & 0.0045 & -0.0013 & 0.0031 & 0.1980 \\
\hline & Bia-Ldt Mt2 $_{2}$ & & & & & & \\
\hline HB1 & $\mathrm{O}_{76} \mathrm{H} \cdots \mathrm{S}_{70}$ & 0.0233 & 0.0569 & 0.0153 & 0.0011 & 0.0163 & 0.0388 \\
\hline \multirow[t]{2}{*}{ HB2 } & $\mathrm{C}_{75} \mathrm{H} \cdots \mathrm{C}_{45}$ & 0.0072 & 0.0245 & 0.0047 & -0.0014 & 0.0033 & 0.1500 \\
\hline & Mero-Ldt Mt2 & & & & & & \\
\hline HB1 & $\mathrm{O}_{86} \mathrm{H} \cdots \mathrm{S}_{81}$ & 0.0245 & 0.0594 & 0.0161 & 0.0013 & 0.0175 & 0.0393 \\
\hline HB2 & $\mathrm{C}_{85} \mathrm{H} \cdots \mathrm{C}_{56} \mathrm{~N}$ & 0.0080 & 0.0275 & 0.0054 & -0.0015 & 0.0039 & 0.1495 \\
\hline
\end{tabular}

KEG, Lagrangian kinetic energy density $\boldsymbol{G}(\boldsymbol{r})$, KEK, Hamiltonian kinetic energy density $\boldsymbol{H}(\boldsymbol{r})$, VIR, Virial filed function $\boldsymbol{V}(\boldsymbol{r})$, Ellipticity $(\varepsilon)$.

The ellipticity $(\varepsilon)$ values of each bond critical point for all carbapenem-Ldt $\mathrm{Mt}_{2}$ complexes are reported in Table 2. Ellipticity is the important measure of the bond's stability i.e. high ellipticity value signifies unstable bonds. ${ }^{74}$ The ellipticity of the carbapenem- Ldt $_{\mathrm{Mt} 2}$ 
complexes ranges from $0.0359-0.6362$ a.u. It is noted that $\mathbf{H B 1}$ is dominant for all complexes. The $\varepsilon$ values for HB1 also follow the same trend of the binding free energies (experimental and theoretical). It is worth pointing out that the hydrogen bonds in the QM region of all carbapenem- Ldt $_{\mathrm{Mt} 2}$ complexes demonstrate stable electrostatic interactions, considering the average amount of ellipticity as $\mathrm{Imi}-\mathrm{Ldt}_{\mathrm{Mt} 2}>\mathrm{Tebi}-\mathrm{Ldt}_{\mathrm{Mt} 2}>\mathrm{Bia}-\mathrm{Ldt}_{\mathrm{Mt} 2} \approx \mathrm{Mero}-\mathrm{Ldt}_{\mathrm{Mt} 2}$ and this trend is consistent with the obtained binding free energies.

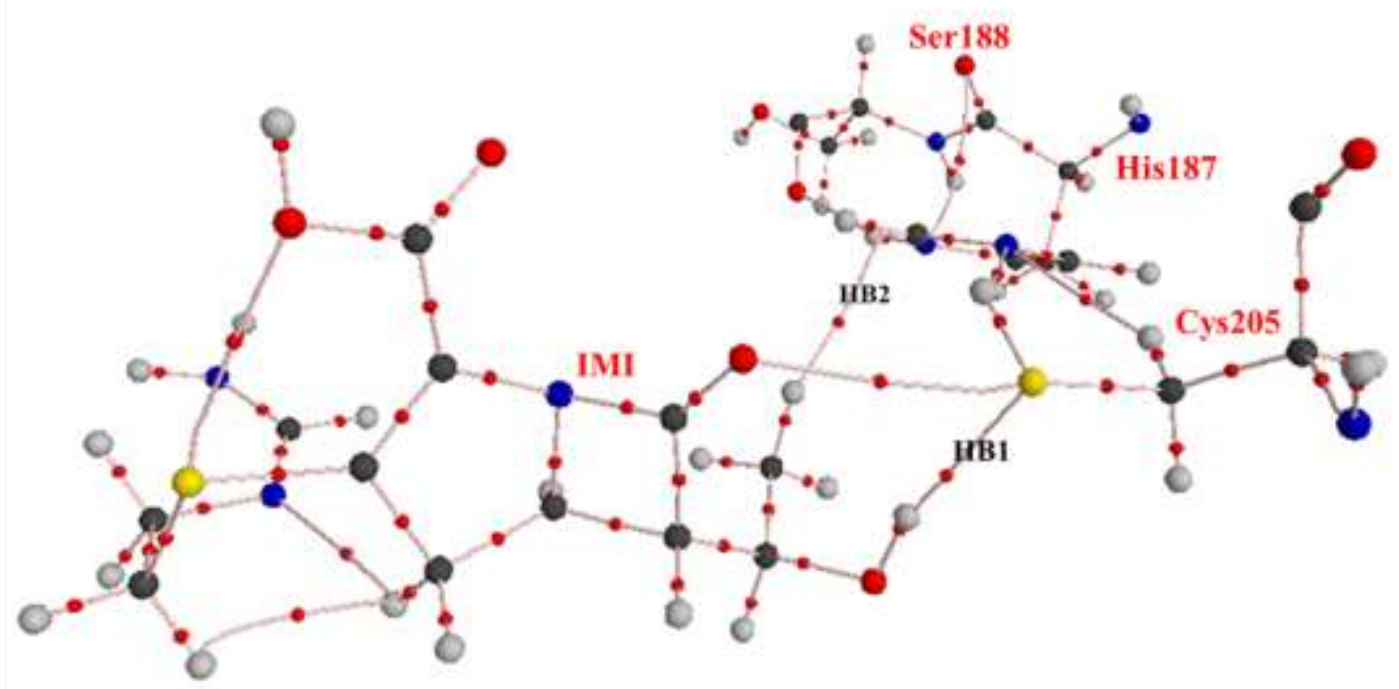

A

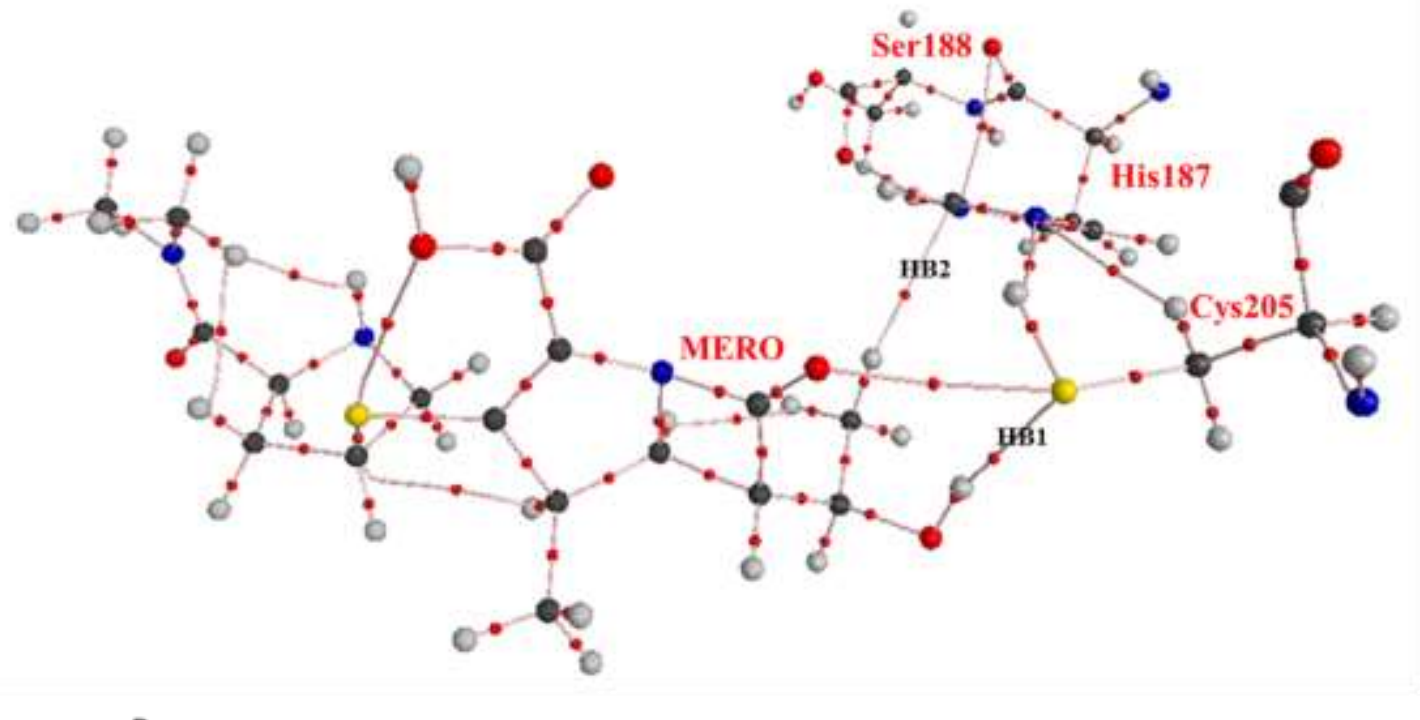

B

Figure 6. Molecular graph of $\mathbf{A}$. Imi- $\mathrm{Ldt}_{\mathrm{Mt} 2}$ and $\mathbf{B}$. Mero- $\mathrm{Ldt}_{\mathrm{M} 2}$ complexes generated using AIM2000 software. Small red spheres and lines correspond to the bond critical points (BCP) and the bond paths, respectively. See details of the molecular graph for other complexes in Figure 7S. 


\section{Natural Bond Orbital analysis}

In the NBO analysis ${ }^{36}$, electronic wave functions are elucidated in terms of a set of occupied Lewis and a set of unoccupied non-Lewis localized orbitals. The delocalization effect can be recognized by the existence of off-diagonal elements of the Fock matrix. The intensities of delocalization interactions are predicted by the second-order perturbation theory $E^{(2) 36}$. Based on the optimized ground state geometries of the QM region of the carbapenem-Ldt $\mathrm{Mt}_{2}$ complexes using the B3LYP/6-31+G(d), the NBO analysis of donor-acceptor (bond-antibonding) interactions have been assessed. The HB1 is also dominant in all complexes. The stabilization energies associated with delocalization of electrons is the strongest in S36... O56-H73 (HB1) of the Imi- Ldt $_{\text {Mt2 }}$ complex by $15.80 \mathrm{kcal} \mathrm{mol}^{-1}$. In the Mero- $\mathrm{Ldt}_{\mathrm{Mt} 2}$ complex, the S81…086-H87 (HB1) have the strongest stabilization energy of $17.45 \mathrm{kcal}$ $\mathrm{mol}^{-1}$ as shown in Table 3. The other carbapenem-Ldt $\mathrm{Mt}_{2}$ complexes also exhibited the strongest stabilization energies in HB1 interactions. This observation reveals that even for the complexes with moderate and weak binding affinities, electron charge transfer will still occur from donor to acceptor units (Table 3). The charge transfer between the lone pair (LP) and the anti-bonding (BD*) orbitals, as shown in Figure 7, exhibit larger stabilization $E^{2}$ values. As a result, this indicates the possibility of electron charge transfer from donors to acceptors. The formation of hydrogen bonds provides sufficient evidence for the considerable electron charge transfer from the lone pair orbital to anti-bonding orbital. Hence, the NBO analysis agrees with the QTAIM results in justifying the stability of the carbapenem-Ldt $\mathrm{Mt}_{2}$ complexes denoted by ONIOM Gibbs free binding interaction energies. 
Table 3. Second-order perturbation energies $\mathrm{E}^{(2)}\left(\mathrm{kcal} \mathrm{mol}^{-1}\right)$ corresponding to the most important charge transfer interaction (donor $\rightarrow$ acceptor) in the carbapenem- $\mathrm{Ldt}_{\mathrm{Mt} 2}$ complexes at the B3LYP/6$31 \mathrm{G}$ level.

\begin{tabular}{llll}
\hline Complex/ Interactions $\quad$ Donor NBO $(i) n(\mathrm{O}) \quad$ Acceptor NBO $(j) \sigma^{*}(\mathrm{O}-\mathrm{H})$ & $\begin{array}{l}E^{(2)}\left(\mathrm{kcalmol}^{-1}\right) \\
(\mathrm{O}) \rightarrow \sigma^{*}(\mathrm{O}-\mathrm{H})\end{array}$
\end{tabular}

\section{Imi-Ldt $_{\text {Mt2 }}$}

HB1

BD (1) S36-H37

$\mathrm{BD} *(1) \mathrm{O} 56-\mathrm{H} 73$

0.22

LP (2) S36

$\mathrm{BD} *(1) \mathrm{O} 56-\mathrm{H} 73$

15.80

HB2

BD (1) C55-H60

BD*(1) $\mathrm{C} 11-\mathrm{H} 12$

0.12

BD (1) C11-H12

$\mathrm{BD} *(1) \mathrm{C} 55-\mathrm{H} 60$

0.28

Tebi-Ldt ${ }_{\text {Mt2 }}$

HB1

BD (1) S36-H37

$\mathrm{BD}^{*}$ (1) $\mathrm{O} 81-\mathrm{H} 82$

0.17

LP (1) S36

BD*(1) O81-H82

1.64

LP (2) S36

BD*(1) O81-H82

15.80

HB2

BD (1) C11-H12

$\mathrm{BD}^{*}(1) \mathrm{C} 80-\mathrm{H} 84$

0.27

Bia-Ldt ${ }_{\text {Mt2 }}$

HB1

BD (1) S70-H71

BD*(1) O76-H79

0.12

LP (1) S70

BD*(1) O76-H79

2.77

LP (2) S70

BD*(1) O76-H79

16.47

HB2

BD (1) C75-H78

BD*(1) $\mathrm{C} 45-\mathrm{H} 46$

0.22

BD (1) C45-H46

BD*(1) $\mathrm{C} 75-\mathrm{H} 78$

0.17

Mero-Ldt $_{\text {Mt2 }}$

\begin{tabular}{|c|c|c|c|}
\hline \multirow[t]{3}{*}{ HB1 } & $\mathrm{BD}$ (1) S81-H82 & $\mathrm{BD}^{*}(1) \mathrm{O} 86-\mathrm{H} 87$ & 0.16 \\
\hline & LP (1) S81 & $\mathrm{BD} *(1) \mathrm{O} 86-\mathrm{H} 87$ & 1.42 \\
\hline & LP (2) S81 & BD*(1) O86-H87 & 17.45 \\
\hline \multirow[t]{3}{*}{ HB2 } & $\mathrm{BD}(1) \mathrm{C} 85-\mathrm{H} 89$ & $\mathrm{BD}^{*}(1) \mathrm{C} 56-\mathrm{N} 58$ & 0.24 \\
\hline & $\mathrm{BD}(2) \mathrm{C} 56-\mathrm{N} 58$ & $\mathrm{BD}^{*}(1) \mathrm{C} 85-\mathrm{H} 89$ & 0.73 \\
\hline & $\mathrm{BD}(2) \mathrm{C} 56-\mathrm{N} 58$ & $\mathrm{BD}^{*}(1) \mathrm{C} 85-\mathrm{H} 89$ & 0.40 \\
\hline
\end{tabular}




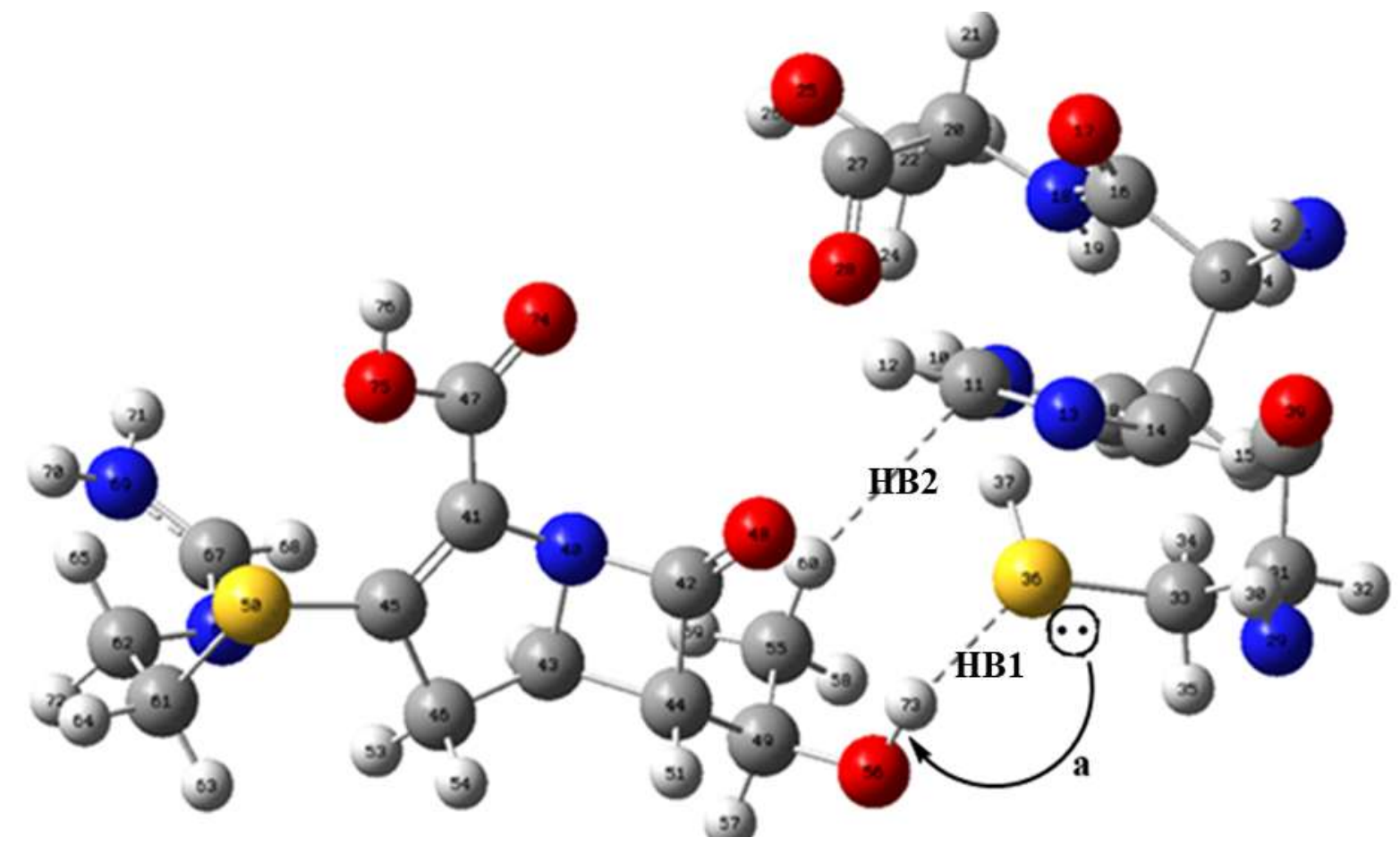

Figure 7. Depiction of electron transfers for Imi- $\mathrm{Ldt}_{\mathrm{Mt} 2}$ complex derived by second-order perturbation theory of NBO analysis. The curved arrows (a) depict the direction of charge transfer: (a) LP (S) $\rightarrow \sigma^{*}$ $(\mathrm{O}-\mathrm{H})$ listed in Table 3.

\section{Conclusion}

In this study, a two-layered ONIOM (B3LYP/6-31+G(d): Amber) model was used to evaluate the efficacy of FDA approved carbapenems antibiotics towards $\operatorname{Ldt}_{\mathrm{Mt} 2}$ by calculating their binding interaction energies, hydrogen bond measurements, AIM and performing NBO analyses. The four carbapenem $-\mathrm{Ldt}_{\mathrm{Mt} 2}$ complexes, namely Imi- $\mathrm{Ldt}_{\mathrm{Mt}}$, Tebi- $\mathrm{Ldt}_{\mathrm{Mt}}$, Bia$\mathrm{Ldt}_{\mathrm{Mt}}$, and Mero - $\mathrm{Ldt}_{\mathrm{Mt}}$, were undertaken for this study. The Gibb's free energies $(\Delta \mathrm{G})$ obtained in this study corresponded with the experimental trend. As for enthalpies $(\Delta \mathrm{H})$ and entropies $(\Delta S)$, the favorable contributions of ligand-receptor electrostatic, hydrogen bond and van der Waals interactions to binding free energies for calculated complexes (carbapenems$\mathrm{Ldt}_{\mathrm{M} \text { 2) }}$ suggests a suitable theoretical model. Moreover, the QTAIM topological indices provide an accurate indication of the critical hydrogen bond formation that contribute to the stability of the carbapenem- $-\mathrm{Ldt}_{\mathrm{Mt} 2}$ complexes. The AIM analysis agrees with the extent of charge transfer between carbapenems and $\mathrm{Ldt}_{\mathrm{Mt} 2}$ shown by the $\mathrm{NBO}$ second order perturbation theory. NBO analysis was used to elucidate the data concerning charge transfer of electrons between carbapenems and Ldt $\mathrm{Mt}_{\mathrm{L}}$. Both analyses reveal that the prominent non-covalent interactions within the complexes correlates to the ONIOM calculated binding free energies. 
The ONIOM method provides better relative binding free energies of these complexes than the previous molecular dynamics studies. The outcome of this study highlights the nature of the non-covalent interactions of $\mathrm{Ldt}_{\mathrm{Mt} 2}$ with carbapenems which could be also applied and extended for rational drug design of novel anti-TB drugs; which will address the computeraided drug design challenges.

\section{Competing interests}

The authors declare that they have no competing interests.

\section{Acknowledgements}

We thank the College of Health Sciences (CHS), Aspen Pharmacare, MRC and NRF for financial support. We are also grateful to the CHPC (www.chpc.ac.za) and UKZN cluster for computational resources.

\section{References}

[1] (WHO), W. H. O. (2017) World Health Organization. Global tuberculosis report 2016 [cited 16 January 2018]; Available from: www.who.int/tb/publications/global_report/en/.

[2] Cegielski, J. P. (2010) Extensively drug-resistant tuberculosis:"there must be some kind of way out of here", Clin. Infect. Dis. 50, S195-S200.

[3] Cole, S. T., and Riccardi, G. (2011) New tuberculosis drugs on the horizon, Curr. Opin. Microbiol. 14, 570-576.

[4] Gandhi, N. R., Moll, A., Sturm, A. W., Pawinski, R., Govender, T., Lalloo, U., Zeller, K., Andrews, J., and Friedland, G. (2006) Extensively drug-resistant tuberculosis as a cause of death in patients co-infected with tuberculosis and HIV in a rural area of South Africa, The Lancet 368, 15751580.

[5] Organization, W. H. (2014) World Health Organization global tuberculosis report, Geneva: World Health Organization(accessed on 14 February 2017).

[6] Gupta, R., Lavollay, M., Mainardi, J. L., Arthur, M., Bishai, W. R., and Lamichhane, G. (2010) The Mycobacterium tuberculosis protein $\operatorname{Ldt}_{\mathrm{Mt2} 2}$ is a nonclassical transpeptidase required for virulence and resistance to amoxicillin, Nat. Med. 16, 466-469.

[7] Mainardi, J.-L., Villet, R., Bugg, T. D., Mayer, C., and Arthur, M. (2008) Evolution of peptidoglycan biosynthesis under the selective pressure of antibiotics in Gram-positive bacteria, FEMS Microbiol. Rev. 32, 386-408.

[8] Lavollay, M., Arthur, M., Fourgeaud, M., Dubost, L., Marie, A., Veziris, N., Blanot, D., Gutmann, L., and Mainardi, J.-L. (2008) The peptidoglycan of stationary-phase Mycobacterium tuberculosis predominantly contains cross-links generated by L, D-transpeptidation, J. Bacteriol. 190, 43604366.

[9] Erdemli, S. B., Gupta, R., Bishai, W. R., Lamichhane, G., Amzel, L. M., and Bianchet, M. A. (2012) Targeting the cell wall of Mycobacterium tuberculosis: structure and mechanism of L,Dtranspeptidase 2, Structure 20, 2103-2115.

[10] Li, W. J., Li, D. F., Hu, Y. L., Zhang, X. E., Bi, L. J., and Wang, D. C. (2013) Crystal structure of L,Dtranspeptidase Ldt $_{\mathrm{Mt} 2}$ in complex with meropenem reveals the mechanism of carbapenem against Mycobacterium tuberculosis, Cell Res. 23, 728-731. 
[11] Papp-Wallace, K. M., Endimiani, A., Taracila, M. A., and Bonomo, R. A. (2011) Carbapenems: past, present, and future, Antimicrob. Agents Chemother. 55, 4943-4960.

[12] Wietzerbin, J., Das, B. C., Petit, J. F., Lederer, E., Leyh-Bouille, M., and Ghuysen, J. M. (1974) Occurrence of D-alanyl-(D)-meso-diaminopimelic acid and meso-diaminopimelyl-mesodiaminopimelic acid interpeptide linkages in the peptidoglycan of Mycobacteria, Biochemistry 13, 3471-3476.

[13] Böth, D., Steiner, E. M., Stadler, D., Lindqvist, Y., Schnell, R., and Schneider, G. (2013) Structure of $\mathrm{Ldt}_{\mathrm{Mt} 2}$, an L, D-transpeptidase from Mycobacterium tuberculosis, Acta Crystallogr. D. 69, 432441.

[14] Cordillot, M., Dubée, V., Triboulet, S., Dubost, L., Marie, A., Hugonnet, J.-E., Arthur, M., and Mainardi, J.-L. (2013) In vitro cross-linking of Mycobacterium tuberculosis peptidoglycan by I, $\mathrm{d}$-transpeptidases and inactivation of these enzymes by carbapenems, Antimicrob. Agents Chemother. 57, 5940-5945.

[15] Correale, S., Ruggiero, A., Capparelli, R., Pedone, E., and Berisio, R. (2013) Structures of free and inhibited forms of the L, D-transpeptidase LdtMt1 from Mycobacterium tuberculosis, Acta Crystallogr. D. 69, 1697-1706.

[16] Dubée, V., Triboulet, S., Mainardi, J.-L., Ethève-Quelquejeu, M., Gutmann, L., Marie, A., Dubost, L., Hugonnet, J.-E., and Arthur, M. (2012) Inactivation of Mycobacterium tuberculosis L, Dtranspeptidase LdtMt1 by carbapenems and cephalosporins, Antimicrob. Agents Chemother. $56,4189-4195$.

[17] Schoonmaker, M. K., Bishai, W. R., and Lamichhane, G. (2014) Nonclassical transpeptidases of Mycobacterium tuberculosis alter cell size, morphology, the cytosolic matrix, protein localization, virulence, and resistance to $\beta$-lactams, J. Bacteriol. 196, 1394-1402.

[18] Kim H. S, K. J., Im H. N, Yoon J. Y, An D. R, Yoon H. J, Kim J. Y, Min H. K, Kim S. J, Lee J. Y, Han B. W, Suh S. W. (2013) Structural basis for the inhibition of Mycobacterium tuberculosis L,Dtranspeptidase by meropenem, a drug effective against extensively drug-resistant strains, Acta Crystallogr D Biol Crystallogr D69, 420-431.

[19] Nizami, B., Sydow, D., Wolber, G., and Honarparvar, B. (2016) Molecular insight on the binding of NNRTI to K103N mutated HIV-1 RT: molecular dynamics simulations and dynamic pharmacophore analysis, Mol. BioSyst. 12, 3385-3395.

[20] Honarparvar, B., Pawar, S. A., Alves, C. N., Lameira, J., Maguire, G. E., Silva, J. R. A., Govender, T., and Kruger, H. G. (2015) Pentacycloundecane lactam vs lactone norstatine type protease HIV inhibitors: binding energy calculations and DFT study, J. Biomed. Sci. 22, 15.

[21] Honarparvar, B., Govender, T., Maguire, G. E., Soliman, M. E., and Kruger, H. G. (2013) Integrated approach to structure-based enzymatic drug design: molecular modeling, spectroscopy, and experimental bioactivity, Chem. Rev 114, 493-537.

[22] Silva, J. R. A., Bishai, W. R., Govender, T., Lamichhane, G., Maguire, G. E., Kruger, H. G., Lameira, J., and Alves, C. N. (2016) Targeting the cell wall of Mycobacterium tuberculosis: a molecular modeling investigation of the interaction of imipenem and meropenem with L, Dtranspeptidase 2, J. Biomol. Struct. Dyn. 34, 304-317.

[23] Fakhar, Z., Govender, T., Maguire, G. E. M., Lamichhane, G., Walker, R. C., Kruger, H. G., and Honarparvar, B. (2017) Differential flap dynamics in I,d-transpeptidase2 from mycobacterium tuberculosis revealed by molecular dynamics, Mol. BioSyst. 13, 1223-1234.

[24] Svensson, M., Humbel, S., Froese, R. D., Matsubara, T., Sieber, S., and Morokuma, K. (1996) ONIOM: A multilayered integrated $\mathrm{MO}+\mathrm{MM}$ method for geometry optimizations and single point energy predictions. A test for Diels-Alder reactions and $\mathrm{Pt}(\mathrm{P}(\mathrm{t}-\mathrm{Bu}) 3$ ) $2+\mathrm{H} 2$ oxidative addition, J. Phys. Chem. A 100, 19357-19363.

[25] Dapprich, S., Komáromi, I., Byun, K. S., Morokuma, K., and Frisch, M. J. (1999) A new ONIOM implementation in Gaussian98. Part I. The calculation of energies, gradients, vibrational frequencies and electric field derivatives, Comput. Theor. Chem 461, 1-21. 
[26] Vreven, T., and Morokuma, K. (2000) On the application of the IMOMO (integrated molecular orbital+ molecular orbital) method, J. Comput. Chem 21, 1419-1432.

[27] Karadakov, P. B., and Morokuma, K. (2000) ONIOM as an efficient tool for calculating NMR chemical shielding constants in large molecules, Chem. Phys. Lett 317, 589-596.

[28] Banáš, P., Jurečka, P., Walter, N. G., Šponer, J., and Otyepka, M. (2009) Theoretical studies of RNA catalysis: hybrid QM/MM methods and their comparison with MD and QM, Methods 49, 202216.

[29] Morokuma, K. (2009) Theoretical studies of structure, function and reactivity of molecules - A personal account, Proc. Jpn. Acad. Ser. B Phys. Biol. Sci. 85, 167-182.

[30] Maseras F., M. K. (1995) IMOMM: A new integrated ab initio + molecular mechanics geometry optimization scheme of equilibrium structures and transition states. , J. Comp. Chem. 16, 1170-1179.

[31] Zheng, F., and Zhan, C.-G. (2008) Rational design of an enzyme mutant for anti-cocaine therapeutics, J. Comput-Aided. Mol. Des. 22, 661-671.

[32] Ruangpornvisuti, V. (2004) Recognition of carboxylate and dicarboxylates by azophenol-thiourea derivatives: a theoretical host-guest investigation, Comput. Theor. Chem 686, 47-55.

[33] Samanta, P. N., and Das, K. K. (2016) Prediction of binding modes and affinities of 4-substituted2, 3, 5, 6-tetrafluorobenzenesulfonamide inhibitors to the carbonic anhydrase receptor by docking and ONIOM calculations, J Mol Graph Model 63, 38-48.

[34] Promsri, S., Chuichay, P., Sanghiran, V., Parasuk, V., and Hannongbua, S. (2005) Molecular and electronic properties of HIV-1 protease inhibitor C 60 derivatives as studied by the ONIOM method, Comput. Theor. Chem 715, 47-53.

[35] Bader, R., and Molecules, A. I. (1990) A Quantum Theory, Clarendon, Oxford, England.

[36] Reed, A. E., Curtiss, L. A., and Weinhold, F. (1988) Intermolecular interactions from a natural bond orbital, donor-acceptor viewpoint, Chemical Reviews 88, 899-926.

[37] Li, W.-J., Li, D.-F., Hu, Y.-L., Zhang, X.-E., Bi, L.-J., and Wang, D.-C. (2013) Crystal structure of L, Dtranspeptidase $\mathrm{Ldt}_{\mathrm{Mt2}}$ in complex with meropenem reveals the mechanism of carbapenem against Mycobacterium tuberculosis, Cell research 23, 728.

[38] The PyMOL Molecular Graphics System, V. S., LLC.

[39] Case, D., Darden, T., Cheatham III, T., Simmerling, C., Wang, J., Duke, R., Luo, R., Crowley, M., Walker, R., and Zhang, W. (2008) AMBER, version 10, University of California: San Francisco, $C A$.

[40] Hornak, V., Abel, R., Okur, A., Strockbine, B., Roitberg, A., Simmerling, C. (2006) Comparison of multiple Amber force fields and development of improved protein backbone parameters, Proteins. Discipline. Protein biochemistry 65, 712-725.

[41] Wang, J. M., Wolf, R. M., Caldwell, J. W., Kollman, P. A., Case, D. A. . (2004) Development and testing of a general amber force field, J. Comput. Chem 25, 1157-1174.

[42] Jorgensen, W. L., Chandrasekhar, J., Madura, J. D., Impey, R. W., and Klein, M. L. (1983) Comparison of simple potential functions for simulating liquid water, J. Chem. Phys 79, 926935.

[43] Harvey M. J., F. G. D. (2009) An Implementation of the Smooth Particle Mesh Ewald Method on GPU Hardware, J. Chem. Theory Comput 5, 2371-2377.

[44] Ryckaert, J. P., Ciccotti, G., Berendsen, H. J. C. . (1977) Numerical integration of the cartesian equations of motion of a system with constraints: Molecular dynamics of $\mathrm{N}$-alkanes, $\mathrm{J}$. Comput. Phys 23, 327-341.

[45] Li, H., Robertson, A. D., and Jensen, J. H. (2005) Very fast empirical prediction and rationalization of protein pKa values, Proteins. Discipline. Protein biochemistry 61, 704-721.

[46] Frisch, M., Trucks, G., Schlegel, H., Scuseria, G., Robb, M., Cheeseman, J., Scalmani, G., Barone, V., Mennucci, B., and Petersson, G. (2009) Gaussian 2009, See Supporting Information $f$ or full citation. 
[47] Kapp, J., Remko, M., and Schleyer, P. v. R. (1996) H2XO and (CH3) 2 XO Compounds (X= C, Si, Ge, $\mathrm{Sn}, \mathrm{Pb}$ ): Double Bonds vs Carbene-Like Structures Can the Metal Compounds Exist at All?, J. Am. Chem. Soc. 118, 5745-5751.

[48] Remko, M., Walsh, O. A., and Richards, W. G. (2001) Theoretical study of molecular structure, tautomerism, and geometrical isomerism of moxonidine: Two-layered ONIOM calculations, $J$. Phys. Chem. A 105, 6926-6931.

[49] Johnson, B. G., Gill, P. M., and Pople, J. A. (1993) The performance of a family of density functional methods, J. Chem. Phys 98, 5612-5626.

[50] Humbel, S., Sieber, S., and Morokuma, K. (1996) The IMOMO method: Integration of different levels of molecular orbital approximations for geometry optimization of large systems: Test for n-butane conformation and SN2 reaction: $\mathrm{RCl}+\mathrm{Cl}-$, J. Chem. Phys 105, 1959-1967.

[51] Kohn, W., Becke, A. D., and Parr, R. G. (1996) Density functional theory of electronic structure, J. Phys. Chem. A 100, 12974-12980.

[52] Neumann, R., Nobes, R. H., and Handy, N. C. (1996) Exchange functionals and potentials, Molecular Physics 87, 1-36.

[53] Becke, A. D. (1993) Density-functional thermochemistry. III. The role of exact exchange, J. Chem. Phys 98, 5648-5652.

[54] Lee, C., Yang, W., and Parr, R. G. (1988) Development of the Colle-Salvetti correlation-energy formula into a functional of the electron density, Physical review B 37, 785.

[55] Hariharan, P. C., and Pople, J. A. (1973) The influence of polarization functions on molecular orbital hydrogenation energies, Theoretica chimica acta 28, 213-222.

[56] Rassolov, V. A., Pople, J. A., Ratner, M. A., and Windus, T. L. (1998) 6-31G* basis set for atoms K through Zn, J. Chem. Phys 109, 1223-1229.

[57] Vreven, T., Byun, K. S., Komáromi, I., Dapprich, S., Montgomery, J. A., Morokuma, K., and Frisch, M. J. (2006) Combining quantum mechanics methods with molecular mechanics methods in ONIOM, J. Chem. Theory Comput 2, 815-826.

[58] Laskowski, R. A., and Swindells, M. B. . (2011) Journal of Chemical Information and Modeling, LigPlott: multiple ligand-protein interaction diagrams for drug discovery 51, 2778-2786.

[59] Panigrahi, S. K. (2008) Strong and weak hydrogen bonds in protein-ligand complexes of kinases: a comparative study, Amino acids 34, 617-633.

[60] Desiraju, G. R. (1996) The C- H $\cdots$ O hydrogen bond: structural implications and supramolecular design, Acc. Chem. Res 29, 441-449.

[61] Panigrahi, S. K., and Desiraju, G. R. (2007) Strong and weak hydrogen bonds in the protein-ligand interface, Proteins. Discipline. Protein biochemistry. 67, 128-141.

[62] Dassault Systèmes BIOVIA, D. S. M. E., Release 2017, San Diego: Dassault Systèmes, 2016.

[63] Bader, R., and Molecules, A. I. (1990) A quantum theory, Clarendon: Oxford, UK.

[64] Popelier, P., and Bader, R. (1992) The existence of an intramolecular C • H • O hydrogen bond in creatine and carbamoyl sarcosine, Chemical physics letters 189, 542-548.

[65] Bianchet, M. A., Pan, Y. H., Basta, L. A. B., Saavedra, H., Lloyd, E. P., Kumar, P., Mattoo, R., Townsend, C. A., and Lamichhane, G. (2017) Structural insight into the inactivation of Mycobacterium tuberculosis non-classical transpeptidase Ldt $\mathrm{Mt2}$ by biapenem and tebipenem, BMC Biochem. 18, 8.

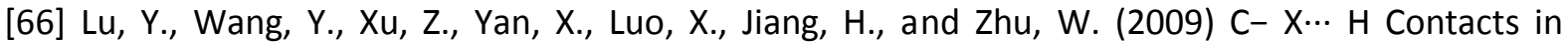
Biomolecular Systems: How They Contribute to Protein- Ligand Binding Affinity, J. Phys. Chem. B 113, 12615-12621.

[67] Patil, R., Das, S., Stanley, A., Yadav, L., Sudhakar, A., and Varma, A. K. (2010) Optimized hydrophobic interactions and hydrogen bonding at the target-ligand interface leads the pathways of drug-designing, PloS one 5, e12029.

[68] Bissantz, C., Kuhn, B., and Stahl, M. (2010) A medicinal chemist's guide to molecular interactions, J. Med. Chem. 53, 5061-5084. 
[69] Parthasarathi, R., Amutha, R., Subramanian, V., Nair, B. U., and Ramasami, T. (2004) Bader's and reactivity descriptors' analysis of DNA base pairs, J. Phys. Chem. A 108, 3817-3828.

[70] Biegler-Konig, F., Schonbohm, J., and Bayles, D. (2001) Software news and updates-AIM2000-A program to analyze and visualize atoms in molecules, pp 545-559, John Wiley \& Sons Inc 605 THIRD AVE, NEW YORK, NY 10158-0012 USA.

[71] Popelier, P. (1998) Characterization of a dihydrogen bond on the basis of the electron density, J. Phys. Chem. A. 102, 1873-1878.

[72] Bader, R. F. (1990) Atoms in Molecules: a quantum theory, International series of monographs on chemistry, 22, Oxford University Press, Oxford Henkelman G, Arnaldsson A, Jónsson H (2006) A fast and robust algorithm for Bader decomposition of charge density. Comput Mater Sci 36, 354-360.

[73] Nazari, F., and Doroodi, Z. (2010) The substitution effect on heavy versions of cyclobutadiene, Int. J. Quantum Chem. 110, 1514-1528.

[74] Mosapour Kotena, Z., Behjatmanesh-Ardakani, R., and Hashim, R. (2014) AIM and NBO analyses on hydrogen bonds formation in sugar-based surfactants $(\alpha / \beta-d$-mannose and $n$-octyl- $\alpha / \beta-d-$ mannopyranoside): a density functional theory study, Liquid Crystals 41, 784-792. 